\title{
Comparative secretome analysis of Streptomyces scabiei during growth in the presence or absence of potato suberin
}

Doaa Komeil ${ }^{2}$, Rebeca Padilla-Reynaud ${ }^{1}$, Sylvain Lerat ${ }^{1}$, Anne-Marie Simao-Beaunoir ${ }^{1}$ and Carole Beaulieu ${ }^{1 *}$

\begin{abstract}
Background: Suberin is a recalcitrant plant biopolymer composed of a polyphenolic and a polyaliphatic domain. Although suberin contributes to a significant portion of soil organic matter, the biological process of suberin degradation is poorly characterized. It has been suggested that Streptomyces scabiei, a plant pathogenic bacterium, can produce suberin-degrading enzymes. In this study, a comparative analysis of the $S$. scabiei secretome from culture media supplemented or not with potato suberin was carried out to identify enzymes that could be involved in suberin degradation.
\end{abstract}

Methods: S. scabiei was grown in the presence of casein only or in the presence of both casein and suberin. Extracellular proteins from 1-, 3- and 5-day-old supernatants were analyzed by LC-MS/MS to determine their putative functions. Real-time RT-PCR was performed to monitor the expression level of genes encoding several proteins potentially involved in suberin degradation.

Results: The effect of suberin on the extracellular protein profile of S. scabiei strain has been analyzed. A total of 246 proteins were found to be common in the data sets from both casein medium (CM) and casein-suberin medium (CSM), whereas 124 and 139 proteins were detected only in CM or CSM, respectively. The identified proteins could be divided into 19 functional groups. Two functional groups of proteins (degradation of aromatic compounds and secondary metabolism) were only associated with the CSM. A high proportion of the proteins found to be either exclusively produced, or overproduced, in presence of suberin were involved in carbohydrate metabolism. Most of the proteins included in the lipid metabolism class have been detected in CSM. Apart from lipid metabolism proteins, other identified proteins, particularly two feruloyl esterases, may also actively participate in the breakdown of suberin architecture. Both feruloyl esterase genes were overexpressed between 30 to 340 times in the presence of suberin.

Conclusion: This study demonstrated that the presence of suberin in S. scabiei growth medium induced the production of a wide variety of glycosyl hydrolases. Furthermore, this study has allowed the identification of extracellular enzymes that could be involved in the degradation of suberin, including enzymes of the lipid metabolism and feruloyl esterases.

Keywords: Streptomyces scabies, Common scab, Proteomics, Feruloyl esterase, Glycosyl hydrolase, Lipid metabolism, Suberinase

\footnotetext{
* Correspondence: carole.beaulieu@usherbrooke.ca

${ }^{1}$ Centre SÈVE, Département de biologie, Université de Sherbrooke, Québec

J1K 2R1, Canada

Full list of author information is available at the end of the article
}

\section{Biomed Central}

(c) 2014 Komeil et al.; licensee BioMed Central Ltd. This is an Open Access article distributed under the terms of the Creative Commons Attribution License (http://creativecommons.org/licenses/by/4.0), which permits unrestricted use, distribution, and reproduction in any medium, provided the original work is properly credited. The Creative Commons Public Domain Dedication waiver (http://creativecommons.org/publicdomain/zero/1.0/) applies to the data made available in this article, unless otherwise stated. 


\section{Background}

Proteomics has been successfully applied to analyze both intracellular proteins and the secretomes of several microorganisms, including plant pathogens [1]. Both the intracellular proteome [2] and the secretome [3] of the plant pathogenic bacterium Streptomyces scabiei have been analyzed. This pathogen is the predominant causal agent of potato common scab and causes important economic losses in most potato growing-areas [4]. The disease is characterized by shallow, raised, or deep-pitted corky-like lesions on the tuber surface. S. scabiei produces toxins called thaxtomins, which cause hypertrophy and cell death in host plant tissues, and are essential for pathogenicity [4].

Thaxtomin biosynthetic genes are expressed during secondary metabolism in the presence of compounds associated with tuber cell walls: cellobiose and suberin [5]. The intracellular proteomes of $S$. scabiei grown with or without suberin have previously been compared [2]. The addition of the plant polymer to the growth media resulted in an increase in proteins involved in stress response, glycolysis and morphological differentiation. Suberin also appeared to affect secondary metabolism as it caused the overproduction of BldK proteins, which are known to be involved in differentiation and secondary metabolism [2]. Suberin is also known to promote differentiation and secondary metabolism in different Streptomyces species [6].

Suberin is a major constituent of potato skin. This polymer is composed of two spatially distinct but covalentlylinked domains; the polyphenolic domain embedded in the primary cell wall, and the polyaliphatic domain [7]. Suberized lamellae are located between the primary cell wall and the plasma membrane [7]. The polyaromatic domain is a lignin-like structure that mostly contains polyhydroxycinnamates such as feruloyltyramine [7]. The aliphatic moiety of suberin is mainly composed of $\omega$-hydroxyacids, $\alpha, \omega$-diacids, fatty acids, primary alcohols and glycerol $[8,9]$. Glycerol may account for up to $25 \%$ of the total suberin monomers [10]. Nevertheless, the molecular structure of suberin remains speculative although the most recent models propose that ferulic acids link the aliphatic polyester domain of suberin to the neighboring polyaromatics $[9,10]$.

Suberin is one of the most recalcitrant plant molecular structures in nature [6] and microbial degradation of suberin is a process that is poorly characterized. Suberinases are polyesterases produced by a number of fungi that can at least partially depolymerize the lipidic polymer [11]. Some authors have suggested that S. scabiei can also produce suberin-degrading esterases [12] that may be involved in pathogenicity. The purpose of this study was to identify enzymes that could potentially be involved in suberin degradation. S. scabiei EF-35 was grown in culture media containing casein as the sole carbon source or in media containing both casein and suberin. The secretomes associated with these growth conditions were then compared. Enzymes involved in both polysaccharide catabolism and lipid metabolism were up-regulated in the presence of suberin.

\section{Results and discussion}

Comparative analysis of the S. scabiei EF-35 secretome in the presence or absence of suberin

A previous study has allowed the identification, in S. scabiei EF-35, of intracellular soluble proteins that were differentially produced in the presence of suberin [2]. Furthermore, the twin arginine protein transport pathway secretome of another S. scabiei strain has been characterized by 2-D electrophoresis in four different culture media (instant potato mash medium, soy-flour mannitol medium, R5 medium and oat bran medium) [3]. In the present study, the effect of suberin, a polymer associated with potato tuber periderm, on the extracellular protein profile of S. scabiei EF-35 has been analyzed. Extracellular protein profiles of supernatants from S. scabiei EF-35 cultures grown in the presence of casein only or in the presence of both casein and suberin were compared after 1, 3 and 5 days of growth. The proteins were fractionated by one-dimensional electrophoresis and analyzed by LC-MS/MS, as fractionation of secretomes has been shown to increase the overall number of identified proteins by approximately $30 \%$ [13].

A total of 907 different proteins were found in at least one of the media tested and 509 proteins met the filtering criteria. Protein abundance was estimated by spectral counting/protein molecular weight $(\mathrm{kDa})$. While 263 out of 509 proteins were restricted to a specific medium, others were found in both culture media. Proteins found in both media are listed in supporting data (Additional file 1: Table S1). Proteins detected only in casein medium (CM) are presented in Additional file 2: Table S2. A list of proteins with a 5-fold greater abundance in the casein/suberin-containing medium (CSM) compared to $\mathrm{CM}$ is shown in Table 1. Proteins only found in CSM are listed in Table 2. All proteins listed have been divided into 19 functional groups based on their putative functions (Table 3).

Bradford protein assays estimated supernatant protein concentrations in CM to be $280 \pm 113,275 \pm 33$ and $217 \pm$ $10 \mu \mathrm{g} / \mathrm{mL}$ in $1-, 3$ - and 5-day-old cultures, respectively. In CSM, protein concentrations were estimated to be $361 \pm$ 45, $350 \pm 13$ and $285 \pm 9 \mu \mathrm{g} / \mathrm{mL}$ in 1-, 3- and 5-day-old cultures, respectively. This higher production of extracellular proteins in CSM may reflect the recalcitrant nature of suberin [6]. Because of the complexity of plant cell walls, some microorganisms secrete up to $50 \%$ of their total protein during growth on such a substrate [14]. Although the majority of the proteins $(69.3 \%)$ found in the supernatants were predicted to have an extracellular 
Table 1 Proteins produced by Streptomyces scabiei with a 5-fold greater abundance in casein-suberin medium

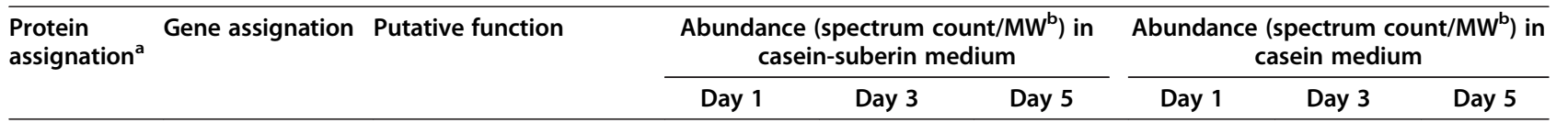

Translational, ribosomal structure and biogenesis

\begin{tabular}{|c|c|c|c|c|c|c|c|c|}
\hline C9Z240 & SCAB_25251 ${ }^{d}$ & $\begin{array}{l}\text { Polyribonucleotide } \\
\text { nucleotidyltransferase }\end{array}$ & $0.04 \pm 0.03$ & $0.25 \pm 0.10$ & $0.22 \pm 0.06$ & $0.01 \pm 0.01$ & $n d^{c}$ & $0.01 \pm 0.01$ \\
\hline C9Z3N7 & SCAB_25991 ${ }^{d}$ & Ribosome recycling factor & $0.43 \pm 0.13$ & nd & nd & $0.08 \pm 0.07$ & $0.03 \pm 0.05$ & $0.10 \pm 0.10$ \\
\hline С9Z3Р0 & SCAB_26021 ${ }^{d}$ & 30 S ribosomal protein S2 & $0.23 \pm 0.12$ & $0.05 \pm 0.02$ & nd & $0.03 \pm 0.05$ & nd & nd \\
\hline C9Z3Q3 & SCAB_26151 ${ }^{d}$ & 50 ribosomal protein L19 & $0.67 \pm 0.32$ & $1.13 \pm 0.56$ & $0.68 \pm 0.25$ & $0.10 \pm 0.18$ & nd & nd \\
\hline C9YW46 & SCAB_3662 $1^{d}$ & 305 ribosomal protein 59 & $0.42 \pm 0.24$ & $0.35 \pm 0.20$ & $0.11 \pm 0.06$ & $0.12 \pm 0.13$ & nd & nd \\
\hline C9YW47 & SCAB_36631 ${ }^{d}$ & $50 S$ ribosomal protein $\mathrm{L} 13$ & $0.25 \pm 0.13$ & $0.24 \pm 0.10$ & $0.10 \pm 0.03$ & $0.02 \pm 0.04$ & nd & nd \\
\hline C9YW61 & SCAB_36771 ${ }^{d}$ & 30 S ribosomal protein $\mathrm{S} 5$ & $0.33 \pm 0.06$ & $0.38 \pm 0.05$ & $0.01 \pm 0.02$ & $0.13 \pm 0.23$ & nd & nd \\
\hline C9YW63 & SCAB_36791 ${ }^{d}$ & 50 S ribosomal protein L6 & $0.18 \pm 0.12$ & $0.33 \pm 0.16$ & $0.02 \pm 0.03$ & $0.02 \pm 0.03$ & nd & nd \\
\hline C9YW64 & SCAB_36801 ${ }^{d}$ & $30 S$ ribosomal protein $\mathrm{S} 8$ & $0.17 \pm 0.15$ & $0.64 \pm 0.45$ & $0.12 \pm 0.21$ & $0.02 \pm 0.04$ & nd & nd \\
\hline C9YW68 & SCAB_36841 & $50 S$ ribosomal protein L14 & $0.21 \pm 0.04$ & $0.63 \pm 0.47$ & $0.54 \pm 0.45$ & $0.05 \pm 0.09$ & nd & nd \\
\hline C9YW72 & SCAB_36881 $1^{d}$ & $30 S$ ribosomal protein $\$ 3$ & $0.17 \pm 0.09$ & $0.09 \pm 0.08$ & $0.01 \pm 0.03$ & $0.02 \pm 0.04$ & nd & nd \\
\hline C9YW73 & SCAB_36891 ${ }^{d}$ & 50 S ribosomal protein L22 & $0.44 \pm 0.16$ & $0.85 \pm 0.60$ & $0.67 \pm 0.40$ & $0.08 \pm 0.13$ & nd & nd \\
\hline C9YW77 & SCAB_36931 ${ }^{d}$ & $50 S$ ribosomal protein $L 4$ & $0.62 \pm 0.13$ & $1.00 \pm 0.20$ & $0.66 \pm 0.06$ & $0.10 \pm 0.14$ & nd & nd \\
\hline C9YW78 & SCAB_36941 ${ }^{d}$ & $50 S$ ribosomal protein $L 3$ & $0.55 \pm 0.10$ & $0.96 \pm 0.26$ & $0.56 \pm 0.15$ & $0.04 \pm 0.08$ & nd & nd \\
\hline C9YW94 & SCAB_37111 ${ }^{d}$ & 30 S ribosomal protein S7 & $0.51 \pm 0.18$ & $0.23 \pm 0.24$ & nd & $0.04 \pm 0.07$ & nd & nd \\
\hline C9ZAN5 & SCAB_4612 ${ }^{d}$ & $30 \mathrm{~S}$ ribosomal protein $\mathrm{S} 18$ & $0.30 \pm 0.06$ & $0.17 \pm 0.18$ & $0.06 \pm 0.09$ & $0.04 \pm 0.06$ & nd & nd \\
\hline C9Z656 & SCAB_75031 ${ }^{d}$ & 30 s ribosomal protein $\$ 4$ & $0.51 \pm 0.32$ & $0.45 \pm 0.14$ & $0.04 \pm 0.04$ & $0.01 \pm 0.02$ & nd & nd \\
\hline \multicolumn{9}{|c|}{ Transcription } \\
\hline $9 \mathrm{ZAB5}$ & SCAB_30041 ${ }^{d}$ & $\begin{array}{l}\text { Cyclic nucleotide-binding } \\
\text { protein }\end{array}$ & $0.03 \pm 0.01$ & $0.18 \pm 0.11$ & $0.17 \pm 0.01$ & $0.03 \pm 0.06$ & nd & nd \\
\hline
\end{tabular}

Cell wall/membrane/envelope biogenesis

$\begin{array}{lll}\text { C9YUC5 } & \text { SCAB_4961 } & \text { Glucuronoxylanase XynC } \\ \text { C9Z8V2 } & \text { SCAB_45141 } & \begin{array}{l}\text { D-alanyl-D-alanine } \\ \text { carboxypeptidase }\end{array}\end{array}$

$\begin{array}{cccccc}0.15 \pm 0.09 & 0.30 \pm 0.21 & 0.26 \pm 0.10 & \text { nd } & \text { nd } & 0.04 \pm 0.03 \\ 0.04 \pm 0.02 & 0.42 \pm 0.07 & 0.40 \pm 0.12 & 0.04 \pm 0.05 & \text { nd } & \text { nd }\end{array}$

Defense mechanisms and virulence
C97785

\begin{abstract}
SCAB_44161 ${ }^{\text {d }}$
\end{abstract}
$\beta$-lactamase
C9Z160 SCAB_5644
Protease

Differentiation

$\begin{array}{lll}\text { C9Z7Z77 SCAB_89661 } & \begin{array}{l}\text { Factor } C \text { morphological } \\ \text { differentiation homolog }\end{array}\end{array}$

Energy production and conversion

$\begin{array}{lll}\text { C9Z8E8 } & \text { SCAB_28761 } & \text { ATP synthase subunit } \beta \\ \text { C9Z8F0 } & \text { SCAB_28781 } & \text { ATP synthase subunit a } \\ \text { C9ZGW6 } & \text { SCAB_34651 } & \text { Oxidoreductase } \\ \text { C9ZE86 } & \text { SCAB_79151 } & \text { Cytokinin dehydrogenase }\end{array}$

Lipid metabolism

\begin{tabular}{|c|c|c|}
\hline C9Z707 & $S C A B \_28481^{d}$ & $\begin{array}{l}\text { Acetyl-CoA C- } \\
\text { acetyltransferase FadA }\end{array}$ \\
\hline C9Z5Z2 & SCAB_74351 & $\begin{array}{l}\text { Glycerophosphoryl diester } \\
\text { phosphodiesterase }\end{array}$ \\
\hline C9ZCRO & SCAB_78851 & $\begin{array}{l}\text { Sphingolipid ceramide } \\
\text { N-deacylase }\end{array}$ \\
\hline
\end{tabular}

$\begin{array}{cccccc}0.43 \pm 0.07 & 0.51 \pm 0.17 & 0.45 \pm 0.12 & 0.02 \pm 0.04 & \text { nd } & \text { nd } \\ 0.39 \pm 0.23 & 0.00 \pm 0.01 & \text { nd } & \text { nd } & 0.21 \pm 0.02 & 0.11 \pm 0.05\end{array}$

nd

$0.14 \pm 0.05 \quad 0.11 \pm 0.06$

nd

nd

$0.01 \pm 0.02$
$0.07 \pm 0.11$
$0.05 \pm 0.06$
$0.02 \pm 0.04$
nd

$0.04 \pm 0.03 \quad 0.02 \pm 0.03$

$0.09 \pm 0.02$

$0.24 \pm 0.07$

$0.23 \pm 0.07$

$0.23 \pm 0.04$

$0.01 \pm 0.01$

$0.12 \pm 0.05 \quad 0.03 \pm 0.03$

$0.06 \pm 0.07$

$0.13 \pm 0.04$

$0.06 \pm 0.05$

$0.06 \pm 0.03$

$0.04 \pm 0.05$

$0.05 \pm 0.08$

$0.08 \pm 0.10$

$0.21 \pm 0.03$

nd

nd

$0.05 \pm 0.05 \quad 0.03 \pm 0.05$

$0.15 \pm 0.18 \quad 0.04 \pm 0.03$ 


\begin{tabular}{|c|c|c|c|c|c|c|c|c|}
\hline \multicolumn{9}{|c|}{ Carbohydrate metabolism } \\
\hline C9ZBE6 & SCAB_0631 & a-L-fucosidase & $0.03 \pm 0.00$ & $0.08 \pm 0.02$ & $0.06 \pm 0.03$ & nd & nd & $0.01 \pm 0.02$ \\
\hline C9YSR8 & SCAB_3851 & Fucosidase & $0.18 \pm 0.02$ & $0.41 \pm 0.16$ & $0.35 \pm 0.11$ & nd & nd & $0.00 \pm 0.01$ \\
\hline C9YSSO & SCAB_3881 & Arabinofuranosidase & $0.13 \pm 0.01$ & $0.39 \pm 0.13$ & $0.32 \pm 0.15$ & nd & $0.18 \pm 0.16$ & $0.04 \pm 0.00$ \\
\hline C9YSS1 & SCAB_3891 & a-galactosidase & $0.10 \pm 0.06$ & $0.22 \pm 0.21$ & $0.13 \pm 0.11$ & nd & $0.01 \pm 0.01$ & nd \\
\hline C9YVN3 & SCAB_5851 & Putative secreted protein & $0.01 \pm 0.01$ & $0.04 \pm 0.03$ & $0.04 \pm 0.04$ & nd & $0.02 \pm 0.01$ & nd \\
\hline C9YVP9 & SCAB_6021 & Endo $\beta$-1.4-xylanase & $0.29 \pm 0.13$ & $0.67 \pm 0.20$ & $0.65 \pm 0.19$ & nd & $0.04 \pm 0.04$ & nd \\
\hline C9Z0D5 & SCAB_8871 & Endoglucanase & $0.03 \pm 0.00$ & $0.05 \pm 0.02$ & $0.08 \pm 0.05$ & nd & $0.02 \pm 0.01$ & $0.02 \pm 0.01$ \\
\hline C9Z1T6 & SCAB_9291 & Lactonase & nd & $0.14 \pm 0.05$ & $0.20 \pm 0.07$ & nd & $0.02 \pm 0.03$ & nd \\
\hline C9Z507 & SCAB_11431 & Glycosyl hydrolase & $0.39 \pm 0.10$ & $0.88 \pm 0.30$ & $0.64 \pm 0.17$ & nd & $0.42 \pm 0.13$ & $0.33 \pm 0.14$ \\
\hline C9Z878 & SCAB_13491 & Glycosyl hydrolase & nd & $0.03 \pm 0.02$ & $0.04 \pm 0.02$ & nd & nd & $0.01 \pm 0.01$ \\
\hline C9ZD50 & SCAB_16431 & Cellulase & $0.43 \pm 0.29$ & $1.52 \pm 0.86$ & $1.04 \pm 0.61$ & nd & $0.93 \pm 0.72$ & $0.39 \pm 0.04$ \\
\hline C9ZD59 & SCAB_16521 & Arabinofuranosidase & $0.38 \pm 0.12$ & $1.07 \pm 0.39$ & $0.96 \pm 0.36$ & nd & $0.33 \pm 0.24$ & $0.33 \pm 0.17$ \\
\hline C9ZEP9 & SCAB_17001 & Cellulase & $0.05 \pm 0.04$ & $1.05 \pm 0.47$ & $1.05 \pm 0.38$ & nd & $0.29 \pm 0.14$ & $0.19 \pm 0.14$ \\
\hline C9ZEQ0 & SCAB_17011 & Cellulase & $0.15 \pm 0.04$ & $0.85 \pm 0.26$ & $0.73 \pm 0.21$ & nd & $0.02 \pm 0.02$ & $0.02 \pm 0.02$ \\
\hline C9YT14 & SCAB_19051 & Solute-binding lipoprotein & nd & $0.12 \pm 0.05$ & $0.21 \pm 0.11$ & nd & $0.09 \pm 0.08$ & $0.02 \pm 0.02$ \\
\hline C9YT63 & SCAB_19561 & $\beta$-xylosidase & $0.09 \pm 0.10$ & $0.23 \pm 0.17$ & $0.24 \pm 0.17$ & nd & $0.36 \pm 0.18$ & $0.20 \pm 0.05$ \\
\hline C9YUL1 & SCAB_19941 & Glycosyl hydrolase & $0.47 \pm 0.08$ & $0.46 \pm 0.29$ & $0.33 \pm 0.18$ & $0.04 \pm 0.03$ & $0.38 \pm 0.12$ & $0.26 \pm 0.12$ \\
\hline C9YYV2 & SCAB_22931 & Arabinofuranosidase & $0.24 \pm 0.07$ & $0.40 \pm 0.20$ & $0.35 \pm 0.14$ & nd & $0.22 \pm 0.16$ & $0.12 \pm 0.03$ \\
\hline C9Z271 & SCAB_25571 & Glycosyl hydrolase & nd & $0.22 \pm 0.17$ & $0.17 \pm 0.07$ & nd & $0.10 \pm 0.09$ & nd \\
\hline C9YUZ2 & SCAB_36371 & Xylanase/cellulase & $0.24 \pm 0.10$ & $0.51 \pm 0.16$ & $0.47 \pm 0.13$ & $0.02 \pm 0.02$ & $0.23 \pm 0.18$ & $0.14 \pm 0.09$ \\
\hline C9Z5L1 & SCAB_42951 & $\begin{array}{l}\text { Glucose / Sorbosone } \\
\text { dehydrogenase }\end{array}$ & $0.87 \pm 0.12$ & $4.30 \pm 2.73$ & $4.18 \pm 1.77$ & $0.14 \pm 0.14$ & $0.91 \pm 0.35$ & $0.60 \pm 0.22$ \\
\hline C9Z737 & SCAB_43661 & $\begin{array}{l}\text { Galactan endo-1.6- } \beta \text { - } \\
\text { galactosidase }\end{array}$ & $0.20 \pm 0.08$ & $0.32 \pm 0.11$ & $0.18 \pm 0.08$ & $0.01 \pm 0.02$ & nd & nd \\
\hline C9Z7AO & SCAB_44311 & a-galactosidase & $0.13 \pm 0.07$ & $0.15 \pm 0.03$ & $0.12 \pm 0.07$ & nd & $0.07 \pm 0.05$ & $0.06 \pm 0.05$ \\
\hline C9Z7A1 & SCAB_44321 & Glycosyl hydrolase & $0.17 \pm 0.05$ & $0.05 \pm 0.05$ & $0.07 \pm 0.04$ & nd & nd & $0.01 \pm 0.01$ \\
\hline C9YTK2 & SCAB_51081 & Cellulase & $0.01 \pm 0.01$ & $0.57 \pm 0.25$ & $0.46 \pm 0.13$ & nd & $0.05 \pm 0.07$ & nd \\
\hline C9Z2N2 & SCAB_57161 & Endo- $\beta$-1.6-galactanase & $0.07 \pm 0.03$ & $0.36 \pm 0.11$ & $0.35 \pm 0.04$ & nd & nd & $0.02 \pm 0.02$ \\
\hline C9Z451 & SCAB_57751 & $\begin{array}{l}\text { Cellobiose-binding } \\
\text { transport system }\end{array}$ & nd & $0.11 \pm 0.07$ & $0.18 \pm 0.06$ & nd & $0.02 \pm 0.02$ & nd \\
\hline C9ZDW4 & SCAB_63891 & $\begin{array}{l}\text { ABC-type xylose transport } \\
\text { system }\end{array}$ & $0.13 \pm 0.10$ & $0.63 \pm 0.14$ & $0.34 \pm 0.18$ & $0.03 \pm 0.04$ & $1.00 \pm 0.30$ & $0.75 \pm 0.15$ \\
\hline C9ZFW2 & SCAB_66021 & $\beta$-xylosidase & $0.09 \pm 0.02$ & $0.23 \pm 0.19$ & $0.23 \pm 0.18$ & nd & $0.01 \pm 0.02$ & $0.01 \pm 0.02$ \\
\hline C9ZFW3 & SCAB_66031 & Arabinofuranosidase & $0.46 \pm 0.06$ & $0.73 \pm 0.26$ & $0.67 \pm 0.14$ & $0.03 \pm 0.03$ & $0.32 \pm 0.15$ & $0.26 \pm 0.12$ \\
\hline C9YY63 & SCAB_69711 ${ }^{d}$ & Phosphoglycerate kinase & $0.07 \pm 0.05$ & $0.02 \pm 0.02$ & $0.00 \pm 0.01$ & $0.02 \pm 0.02$ & nd & nd \\
\hline C9Z2V1 & SCAB_72711 & Endo $\beta$-1.4-xylanase & $0.29 \pm 0.12$ & $0.20 \pm 0.11$ & $0.25 \pm 0.05$ & nd & nd & $0.05 \pm 0.05$ \\
\hline C9Z4J7 & SCAB_74141 & a-N-furanosidase & $0.34 \pm 0.14$ & $0.19 \pm 0.11$ & $0.20 \pm 0.11$ & nd & $0.01 \pm 0.01$ & $0.03 \pm 0.02$ \\
\hline C9ZB22 & SCAB_77441 & a-arabinanase & $0.06 \pm 0.01$ & $0.05 \pm 0.01$ & $0.06 \pm 0.02$ & $0.01 \pm 0.02$ & $0.08 \pm 0.02$ & $0.11 \pm 0.02$ \\
\hline C9ZCR4 & SCAB_78891 & Glycosyl hydrolase & $0.08 \pm 0.06$ & $0.28 \pm 0.16$ & $0.16 \pm 0.06$ & nd & $0.00 \pm 0.01$ & $0.11 \pm 0.06$ \\
\hline C9ZE94 & SCAB_79241 & Arabinofuranosidase & $0.60 \pm 0.16$ & $1.90 \pm 0.61$ & $1.51 \pm 0.68$ & nd & $0.25 \pm 0.11$ & $0.07 \pm 0.06$ \\
\hline C9ZE95 & SCAB_79251 & Xylanase A & $0.79 \pm 0.30$ & $3.26 \pm 1.60$ & $3.17 \pm 1.14$ & $0.04 \pm 0.01$ & $0.13 \pm 0.06$ & $0.12 \pm 0.06$ \\
\hline C9Z041 & SCAB_84801 & Arabinase & $0.17 \pm 0.06$ & $0.46 \pm 0.20$ & $0.45 \pm 0.15$ & $0.03 \pm 0.06$ & $0.61 \pm 0.11$ & $0.47 \pm 0.11$ \\
\hline C9Z115 & SCAB_85231 & Chitinase & $0.17 \pm 0.02$ & $0.80 \pm 0.13$ & $0.46 \pm 0.16$ & nd & $0.42 \pm 0.19$ & $0.26 \pm 0.16$ \\
\hline C9Z351 & SCAB_86311 & Endoglucanase & nd & $0.29 \pm 0.16$ & $0.27 \pm 0.21$ & nd & $0.01 \pm 0.02$ & $0.02 \pm 0.03$ \\
\hline
\end{tabular}


Table 1 Proteins produced by Streptomyces scabiei with a 5-fold greater abundance in casein-suberin medium (Continued)

\begin{tabular}{|c|c|c|c|c|c|c|c|c|}
\hline C9Z674 & SCAB_88071 & Arabinofuranosidase & $0.05 \pm 0.04$ & $0.14 \pm 0.04$ & $0.14 \pm 0.06$ & nd & $0.05 \pm 0.05$ & $0.02 \pm 0.03$ \\
\hline C9Z804 & SCAB_89741 & Cellulose-binding protein & $0.33 \pm 0.09$ & $0.96 \pm 0.23$ & $0.55 \pm 0.12$ & nd & $0.33 \pm 0.14$ & $0.24 \pm 0.03$ \\
\hline C9Z9L5 & SCAB_90081 & Cellulase B & 0.210 .08 & 0.210 .08 & $0.11 \pm 0.03$ & nd & 0.030 .04 & 0.030 .03 \\
\hline C9Z9L6 & SCAB_90091 & Cellulase & $0.30 \pm 0.09$ & $0.85 \pm 0.30$ & $0.67 \pm 0.22$ & nd & $0.07 \pm 0.06$ & $0.06 \pm 0.04$ \\
\hline C9Z9L7 & SCAB_90101 & Cellulase & $0.59 \pm 0.21$ & $1.03 \pm 0.39$ & $0.75 \pm 0.40$ & nd & $0.56 \pm 0.47$ & $0.19 \pm 0.07$ \\
\hline \multicolumn{9}{|c|}{ Amino acid metabolism } \\
\hline c9z1wo & SCAB_9531 ${ }^{d}$ & Catalase-peroxidase & $0.10 \pm 0.01$ & $0.06 \pm 0.06$ & $0.04 \pm 0.05$ & $0.06 \pm 0.05$ & nd & nd \\
\hline C9Z862 & SCAB_13321 & $\begin{array}{l}\text { X-prolyl-dipeptidyl } \\
\text { aminopeptidase }\end{array}$ & $0.21 \pm 0.16$ & $0.28 \pm 0.02$ & $0.18 \pm 0.09$ & $0.02 \pm 0.03$ & nd & nd \\
\hline C9ZGG7 & SCAB_18081 & $\gamma$-glutamyltranspeptidase & $0.39 \pm 0.06$ & $0.32 \pm 0.08$ & $0.32 \pm 0.08$ & $0.01 \pm 0.01$ & nd & $0.02 \pm 0.02$ \\
\hline C9ZGM2 & SCAB_18661 & Serine protease & $0.19 \pm 0.17$ & nd & nd & $0.01 \pm 0.02$ & $0.17 \pm 0.16$ & nd \\
\hline C9Z6V3 & SCAB_27921 & $\begin{array}{l}\text { Neutral zinc } \\
\text { metalloprotease }\end{array}$ & $0.23 \pm 0.12$ & $0.04 \pm 0.02$ & $0.04 \pm 0.01$ & $0.01 \pm 0.02$ & $0.03 \pm 0.03$ & nd \\
\hline C9ZAN4 & SCAB_46111 & $\begin{array}{l}\text { Single-stranded DNA- } \\
\text { binding protein }\end{array}$ & $0.16 \pm 0.05$ & $0.26 \pm 0.12$ & $0.29 \pm 0.09$ & $0.04 \pm 0.06$ & $0.05 \pm 0.05$ & $0.11 \pm 0.05$ \\
\hline C9YTK4 & SCAB_51101 ${ }^{d}$ & $\begin{array}{l}\text { Phosphoserine } \\
\text { aminotransferase }\end{array}$ & $0.14 \pm 0.09$ & $0.41 \pm 0.23$ & $0.50 \pm 0.16$ & $0.06 \pm 0.05$ & $0.09 \pm 0.05$ & $0.07 \pm 0.06$ \\
\hline C9Z498 & SCAB_58251 & $\begin{array}{l}\text { Tripeptidyl } \\
\text { aminopeptidase }\end{array}$ & $0.26 \pm 0.03$ & $0.10 \pm 0.06$ & $0.08 \pm 0.05$ & $0.10 \pm 0.11$ & $0.06 \pm 0.05$ & $0.01 \pm 0.01$ \\
\hline C9ZHG5 & SCAB_66881 $1^{d}$ & Glutamine synthetase & $0.05 \pm 0.04$ & $0.30 \pm 0.09$ & $0.09 \pm 0.05$ & $0.01 \pm 0.02$ & nd & $0.03 \pm 0.01$ \\
\hline C9YY61 & SCAB_69691 & $\begin{array}{l}\text { Zinc-binding } \\
\text { carboxypeptidase }\end{array}$ & $0.16 \pm 0.04$ & $0.05 \pm 0.01$ & $0.04 \pm 0.02$ & $0.02 \pm 0.01$ & $0.07 \pm 0.02$ & $0.05 \pm 0.02$ \\
\hline C9YZP9 & SCAB_70761 & Solute-binding protein & $0.11 \pm 0.05$ & $0.46 \pm 0.22$ & $0.35 \pm 0.17$ & nd & $0.43 \pm 0.19$ & $0.29 \pm 0.08$ \\
\hline C9Z1E7 & SCAB_72231 & Serine protease & $0.28 \pm 0.15$ & $0.58 \pm 0.20$ & $0.50 \pm 0.13$ & $0.01 \pm 0.02$ & $0.25 \pm 0.07$ & $0.24 \pm 0.12$ \\
\hline C9Z1No & SCAB_85681 $1^{d}$ & Tyrosinase & $0.31 \pm 0.05$ & $0.02 \pm 0.03$ & $0.01 \pm 0.01$ & $0.01 \pm 0.02$ & $0.01 \pm 0.02$ & nd \\
\hline \multicolumn{9}{|c|}{ Nucleotide metabolism } \\
\hline C9ZGX4 & SCAB_49491 & 5'-nucleotidase & $0.17 \pm 0.07$ & $0.12 \pm 0.05$ & $0.06 \pm 0.04$ & $0.01 \pm 0.01$ & nd & nd \\
\hline \multicolumn{9}{|c|}{ Inorganic ion metabolism } \\
\hline C9ZH91 & SCAB_66141 & Alkaline phosphatase & $0.21 \pm 0.07$ & $0.25 \pm 0.03$ & $0.18 \pm 0.08$ & nd & nd & $0.03 \pm 0.03$ \\
\hline \multicolumn{9}{|c|}{ General function prediction only } \\
\hline C9Z871 & SCAB_13411 & Oxidoreductase & $1.04 \pm 0.30$ & $0.87 \pm 0.20$ & $0.70 \pm 0.28$ & $0.22 \pm 0.16$ & $0.16 \pm 0.21$ & $0.02 \pm 0.03$ \\
\hline C9ZAW6 & SCAB_62471 & Aminopeptidase & $0.30 \pm 0.07$ & $0.54 \pm 0.28$ & $0.43 \pm 0.17$ & $0.01 \pm 0.01$ & $0.19 \pm 0.14$ & $0.02 \pm 0.02$ \\
\hline C9ZE96 & SCAB_79261 & Feruloyl esterase & $0.30 \pm 0.16$ & $0.48 \pm 0.29$ & $0.41 \pm 0.20$ & nd & $0.03 \pm 0.04$ & $0.03 \pm 0.02$ \\
\hline \multicolumn{9}{|c|}{ Unknown function } \\
\hline C9YVL7 & SCAB_5681 & & $0.44 \pm 0.20$ & $0.61 \pm 0.19$ & $0.54 \pm 0.31$ & nd & $0.11 \pm 0.14$ & nd \\
\hline C9YUN3 & SCAB_20171 & & $0.11 \pm 0.11$ & $0.08 \pm 0.06$ & $0.09 \pm 0.03$ & nd & $0.09 \pm 0.05$ & $0.03 \pm 0.05$ \\
\hline C9ZGQ1 & SCAB_33981 & & $1.19 \pm 0.44$ & $3.88 \pm 1.18$ & $2.99 \pm 0.95$ & $0.18 \pm 0.09$ & $1.95 \pm 0.48$ & $1.33 \pm 0.32$ \\
\hline C9YUT0 & SCAB_35731 & & $0.14 \pm 0.05$ & nd & nd & nd & nd & $0.06 \pm 0.05$ \\
\hline C9Z411 & SCAB_41931 & & $0.07 \pm 0.12$ & nd & nd & nd & $0.07 \pm 0.12$ & nd \\
\hline C9ZHGO & SCAB_66831 & & $0.09 \pm 0.04$ & $0.12 \pm 0.07$ & $0.09 \pm 0.11$ & $0.09 \pm 0.00$ & $0.01 \pm 0.03$ & nd \\
\hline C9Z4J0 & SCAB_74081 & & $0.30 \pm 0.06$ & $0.44 \pm 0.32$ & $0.32 \pm 0.17$ & nd & $0.02 \pm 0.04$ & $0.01 \pm 0.01$ \\
\hline C9Z7P8 & SCAB_75721 & & $0.29 \pm 0.04$ & $0.34 \pm 0.08$ & $0.24 \pm 0.09$ & nd & $0.01 \pm 0.02$ & $0.10 \pm 0.07$ \\
\hline
\end{tabular}

${ }^{a}$ Uniprot accession number; ${ }^{b}$ Data are the mean of three replicates; ${ }^{c}$ nd: not detected; ${ }^{d}$ Protein with intracellular localisation prediction.

localisation by SignalP, SecretomeP, TatFind or TatP analysis, some proteins with a predicted intracellular location were also identified. The proportion of predicted intracellular proteins recovered in the 3- and 5-day-old culture supernatants was higher in CSM than in CM samples (Table 4). A higher concentration of predicted 
Table 2 Proteins specifically produced by Streptomyces scabiei in the casein-suberin medium

\begin{tabular}{|c|c|c|}
\hline $\begin{array}{l}\text { Protein } \\
\text { assignation }^{a}\end{array}$ & $\begin{array}{l}\text { Gene } \\
\text { assignation }\end{array}$ & Putative function \\
\hline \multicolumn{3}{|c|}{ Translational, ribosomal structure and biogenesis } \\
\hline C9Z241 & SCAB_25261 ${ }^{d}$ & 30 S ribosomal protein S15 \\
\hline C9YW50 & SCAB_36661 ${ }^{d}$ & $50 S$ ribosomal protein $\mathrm{L} 17$ \\
\hline C9YW52 & SCAB_36681 ${ }^{d}$ & $30 S$ ribosomal protein $\$ 11$ \\
\hline C9YW59 & SCAB_36751 ${ }^{d}$ & $50 S$ ribosomal protein $\mathrm{L} 15$ \\
\hline C9YW62 & SCAB_36781 ${ }^{d}$ & $50 S$ ribosomal protein L18 \\
\hline C9YW66 & SCAB_36821 ${ }^{d}$ & $50 S$ ribosomal protein $\mathrm{L} 5$ \\
\hline C9YW67 & SCAB_36831 ${ }^{d}$ & $50 S$ ribosomal protein $L 24$ \\
\hline C9YW69 & SCAB_36851 ${ }^{d}$ & $30 S$ ribosomal protein S17 \\
\hline C9YW71 & SCAB_36871 ${ }^{d}$ & $50 S$ ribosomal protein L16 \\
\hline C9YW75 & SCAB_36911 & $50 S$ ribosomal protein $\mathrm{L} 2$ \\
\hline C9YW76 & SCAB_36921 & $50 S$ ribosomal protein $L 23$ \\
\hline C9YW79 & SCAB_36951 ${ }^{d}$ & 30 S ribosomal protein S10 \\
\hline C9YW95 & SCAB_37121 & 30 S ribosomal protein S12 \\
\hline c9zow3 & SCAB_39971 ${ }^{d}$ & 305 ribosomal protein S18 1 \\
\hline C9ZOW7 & SCAB_40011 ${ }^{d}$ & 50 s ribosomal protein L28 2 \\
\hline C9ZAN3 & SCAB_46101 ${ }^{d}$ & $30 S$ ribosomal protein $\mathrm{S} 6$ \\
\hline C9Z218 & SCAB_56731 ${ }^{d}$ & Ribonuclease PH \\
\hline $\mathrm{C} 9 \mathrm{Z7H} 2$ & SCAB_60151 ${ }^{d}$ & $50 S$ ribosomal protein L21 \\
\hline $\mathrm{C} 9 \mathrm{Z7H} 3$ & SCAB_60161 ${ }^{d}$ & $50 S$ ribosomal protein L27 \\
\hline C9YWQ2 & SCAB_69061 ${ }^{d}$ & $30 \mathrm{~S}$ ribosomal protein $\mathrm{S} 1$ \\
\hline C9Z316 & SCAB_73401 ${ }^{d}$ & tRNA (adenine-N(1)-)-methyltransferase \\
\hline $\mathrm{C} 9 \mathrm{Z4H} 9$ & SCAB_73971 & $50 S$ ribosomal protein $L 35$ \\
\hline C9Z4I0 & SCAB_73981 ${ }^{d}$ & $50 S$ ribosomal protein L20 \\
\hline \multicolumn{3}{|l|}{ Transcription } \\
\hline C9Z8G5 & SCAB_28931 ${ }^{d}$ & Transcription termination factor \\
\hline C9YWA1 & SCAB_37181 & DNA-directed RNA polymerase subunit $\beta$ \\
\hline C9YWA2 & SCAB_37191 ${ }^{d}$ & DNA-directed RNA polymerase subunit $\beta$ \\
\hline
\end{tabular}

Abundance (spectrum count/ $\mathrm{MW}^{\mathrm{b}}$ )

Posttranslational modification, protein turnover, chaperones

$\begin{array}{lll}\text { C9YYX4 } & \text { SCAB_23161 } & \text { Membrane protease } \\ \text { C9YYJ3 } & \text { SCAB_84021 } & \text { Carbamoyltransferase }\end{array}$

$\begin{array}{ccc}0.15 \pm 0.26 & 0.38 \pm 0.27 & 0.03 \pm 0.05 \\ 0.43 \pm 0.22 & 0.51 \pm 0.32 & 0.40 \pm 0.32 \\ 0.31 \pm 0.18 & 0.08 \pm 0.11 & \text { nd } \\ 0.21 \pm 0.18 & 0.42 \pm 0.27 & 0.21 \pm 0.20 \\ 0.31 \pm 0.18 & 0.32 \pm 0.11 & 0.24 \pm 0.14 \\ 0.38 \pm 0.21 & 0.33 \pm 0.11 & 0.13 \pm 0.05 \\ 0.06 \pm 0.10 & 0.03 \pm 0.04 & \text { nd } \\ 0.15 \pm 0.10 & 0.38 \pm 0.33 & 0.05 \pm 0.08 \\ 0.15 \pm 0.13 & 0.08 \pm 0.10 & 0.01 \pm 0.03 \\ 0.40 \pm 0.28 & 0.97 \pm 0.24 & 0.60 \pm 0.12 \\ 0.24 \pm 0.10 & 0.32 \pm 0.19 & 0.29 \pm 0.22 \\ 0.36 \pm 0.05 & 0.32 \pm 0.08 & \text { nd } \\ 0.24 \pm 0.11 & 0.14 \pm 0.09 & 0.05 \pm 0.07 \\ \text { nd } & 0.07 \pm 0.18 & \text { nd } \\ \text { nd } & 0.29 \pm 0.10 & 0.17 \pm 0.10 \\ 0.09 \pm 0.16 & 0.23 \pm 0.13 & 0.11 \pm 0.09 \\ 0.04 \pm 0.04 & 0.10 \pm 0.03 & 0.11 \pm 0.03 \\ 0.33 \pm 0.08 & 0.36 \pm 0.31 & 0.25 \pm 0.33 \\ 0.22 \pm 0.11 & 0.48 \pm 0.15 & 0.19 \pm 0.15 \\ 0.07 \pm 0.06 & \text { nd } & \text { nd } \\ 0.02 \pm 0.03 & 0.07 \pm 0.07 & 0.07 \pm 0.04 \\ 0.57 \pm 0.00 & 0.90 \pm 0.44 & 0.48 \pm 0.28 \\ 0.38 \pm 0.35 & 0.42 \pm 0.25 & 0.30 \pm 0.13 \\ \text { nd } & & \\ \text { nd } & 0.14 \pm 0.11 & 0.17 \pm 0.07\end{array}$

Cell wall/membrane/envelope biogenesis

$\begin{array}{lll}\text { C9Z1V1 } & \text { SCAB_9441 } & \text { Sugar isomerase } \\ \text { C9Z234 } & \text { SCAB_25191 } & \text { Dihydrodipicolinate synthase } \\ \text { C9ZAN0 } & \text { SCAB_46061 } & \text { Alanine racemase } \\ \text { C9Z2W0 } & \text { SCAB_72801 } & \text { Glycosyl hydrolase }\end{array}$

$\begin{array}{cll}\text { nd } & 0.00 \pm 0.01 & 0.02 \pm 0.02 \\ 0.02 \pm 0.04 & 0.01 \pm 0.03 & 0.04 \pm 0.05 \\ 0.01 \pm 0.02 & 0.01 \pm 0.02 & 0.01 \pm 0.02 \\ 0.28 \pm 0.15 & 0.90 \pm 0.20 & 0.83 \pm 0.12\end{array}$

Signal transduction mechanism
C9YYC2
SCAB_70311
TerD-like stress protein

nd

$0.16 \pm 0.08$

$0.63 \pm 0.05$

$0.10 \pm 0.02$
Nickel superoxide dismutase

$\beta$-lactamase

$\beta$-lactamase

$\begin{array}{lll}\text { C9ZAA4 } & \text { SCAB_29931 } & \text { Nickel superoxide dismutase } \\ \text { C9YZ91 } & \text { SCAB_38731 } & \text { B-lactamase } \\ \text { C9Z511 } & \text { SCAB_42661 } & \text { B-lactamase }\end{array}$


Table 2 Proteins specifically produced by Streptomyces scabiei in the casein-suberin medium (Continued)

\begin{tabular}{|c|c|c|c|c|c|}
\hline C9ZGZ0 & SCAB_49661 ${ }^{d}$ & Peroxiredoxin & nd & $0.03 \pm 0.06$ & $0.09 \pm 0.11$ \\
\hline C9Z043 & SCAB_84821 & $\beta$-lactamase & $0.02 \pm 0.03$ & $0.18 \pm 0.04$ & $0.11 \pm 0.05$ \\
\hline \multicolumn{6}{|c|}{ Secondary metabolites biosynthesis, transport and catabolism } \\
\hline C9YYT5 & SCAB_8041 & Aminohydrolase & $0.01 \pm 0.02$ & $0.26 \pm 0.11$ & $0.22 \pm 0.11$ \\
\hline C9YWT5 & SCAB_69391 ${ }^{d}$ & Pseudouridine-5'-phosphate glycosidase & nd & $0.03 \pm 0.05$ & $0.02 \pm 0.03$ \\
\hline C9YU69 & SCAB_82441 & Poly(3-hydroxyalkanoate) depolymerase $\mathrm{C}$ & nd & $0.01 \pm 0.01$ & $0.03 \pm 0.03$ \\
\hline C9Z6A5 & SCAB_88391 ${ }^{d}$ & 2-hydroxyhepta-2.4-diene-1.7-dioate isomerase & nd & nd & $0.04 \pm 0.05$ \\
\hline \multicolumn{6}{|c|}{ Energy production and conversion } \\
\hline C9ZBX1 & SCAB_31271 ${ }^{d}$ & Ferredoxin & $0.10 \pm 0.04$ & nd & nd \\
\hline C9YU38 & SCAB_82111 ${ }^{d}$ & Oxidoreductase & $0.03 \pm 0.04$ & $0.02 \pm 0.03$ & $0.01 \pm 0.02$ \\
\hline \multicolumn{6}{|c|}{ Lipid metabolism } \\
\hline C9ZD66 & SCAB_16601 ${ }^{d}$ & CoA transferase & nd & nd & $0.01 \pm 0.02$ \\
\hline $\mathrm{C} 9 \mathrm{Z} 6 \mathrm{Y} 2$ & SCAB_28231 ${ }^{d}$ & Acetate/propionate kinase & nd & $0.01 \pm 0.02$ & $0.04 \pm 0.04$ \\
\hline C9ZGV4 & SCAB_34521 ${ }^{d}$ & Enoyl-CoA hydratase & $0.03 \pm 0.03$ & nd & nd \\
\hline C9Z776 & SCAB_44071 ${ }^{\mathrm{d}}$ & Esterase-lipase & $0.18 \pm 0.05$ & $0.10 \pm 0.07$ & $0.07 \pm 0.02$ \\
\hline C9YTK3 & SCAB_51091 & Esterase-lipase & nd & $0.14 \pm 0.05$ & $0.13 \pm 0.05$ \\
\hline C9YY49 & SCAB_54571 ${ }^{d}$ & Acetyl CoA acyl transferase & $0.01 \pm 0.01$ & $0.10 \pm 0.09$ & $0.14 \pm 0.07$ \\
\hline C9YYE5 & SCAB_70541 & Lipolytic enzyme & $0.07 \pm 0.09$ & nd & nd \\
\hline C9Z7Q3 & SCAB_75771 ${ }^{d}$ & Acyl-CoA dehydrogenase & $0.02 \pm 0.01$ & $0.02 \pm 0.03$ & nd \\
\hline \multicolumn{6}{|c|}{ Degradation of aromatic compounds } \\
\hline C9Z2P6 & SCAB_57301 & 3-oxo-5.6-dehydrosuberyl-CoA semialdehyde dehydrogenase & $0.13 \pm 0.17$ & nd & nd \\
\hline \multicolumn{6}{|c|}{ Carbohydrate metabolism } \\
\hline C9YSY4 & SCAB_4561 & Glycosyl hydrolase & $0.00 \pm 0.00$ & $0.02 \pm 0.02$ & $0.00 \pm 0.00$ \\
\hline C9YMM5 & SCAB_5761 & Glycosyl hydrolase & nd & $0.04 \pm 0.05$ & $0.01 \pm 0.01$ \\
\hline C9YVN4 & SCAB_5861 & Carbohydrate esterase & nd & $0.01 \pm 0.01$ & $0.06 \pm 0.06$ \\
\hline C9YVP5 & SCAB_5981 & Cellulase B & $0.09 \pm 0.06$ & $0.31 \pm 0.19$ & $0.20 \pm 0.13$ \\
\hline C9YVP8 & SCAB_6011 & Glycosyl hydrolase/xylanase & $0.01 \pm 0.01$ & nd & $0.03 \pm 0.04$ \\
\hline C9YX59 & SCAB_6471 & a-L-fucosidase & nd & $0.09 \pm 0.11$ & $0.06 \pm 0.09$ \\
\hline C9Z1U5 & SCAB_9381 & Exo-a-sialidase & $0.16 \pm 0.08$ & $0.34 \pm 0.17$ & $0.37 \pm 0.14$ \\
\hline C9Z885 & SCAB_13561 & Glycosyl hydrolase & $0.02 \pm 0.03$ & $0.01 \pm 0.01$ & $0.00 \pm 0.01$ \\
\hline C9ZBJ5 & SCAB_15481 ${ }^{d}$ & a-mannosidase & nd & $0.04 \pm 0.03$ & $0.07 \pm 0.07$ \\
\hline C9ZD61 & SCAB_16551 & Mannosidase & $0.02 \pm 0.04$ & $0.18 \pm 0.14$ & $0.15 \pm 0.12$ \\
\hline C9ZD71 & SCAB_16651 & SugarP isomerase & $0.01 \pm 0.02$ & $0.05 \pm 0.03$ & $0.02 \pm 0.02$ \\
\hline C9ZEQ1 & SCAB_17021 & Cellulase & $0.04 \pm 0.02$ & $0.47 \pm 0.13$ & $0.36 \pm 0.10$ \\
\hline C9ZEQ3 & SCAB_17041 & Glycosyl transferase & $0.02 \pm 0.03$ & nd & nd \\
\hline C9Z574 & SCAB_26801 & Polysaccharide lyase & nd & $0.04 \pm 0.03$ & $0.05 \pm 0.04$ \\
\hline C9YUZ7 & SCAB_36421 $1^{d}$ & $\beta$-xylosidase & nd & $0.05 \pm 0.02$ & $0.05 \pm 0.02$ \\
\hline C9YW88 & SCAB_37051 & Cellulase/xylanase & $0.09 \pm 0.03$ & $0.24 \pm 0.09$ & $0.35 \pm 0.14$ \\
\hline C9Z725 & SCAB_43531 & Polysaccharide lyase & $0.00 \pm$ & $0.02 \pm 0.03$ & $0.04 \pm 0.05$ \\
\hline C9Z789 & SCAB_44201 & $\beta$-galactosidase & $0.01 \pm 0.02$ & $0.02 \pm 0.02$ & $0.00 \pm 0.00$ \\
\hline C9Z4AO & SCAB_58271 & Glycosyl hydrolase & nd & $0.01 \pm 0.01$ & $0.02 \pm 0.03$ \\
\hline C9ZDV4 & SCAB_63781 & a-L-arabinofuranosidase & nd & $0.01 \pm 0.01$ & $0.04 \pm 0.04$ \\
\hline C9YYE3 & SCAB_70521 & Bifunctional pectate lyase/pectinesterase & $0.02 \pm 0.02$ & nd & nd \\
\hline C9YYE6 & SCAB_70551 & Pectate lyase & $0.91 \pm 0.12$ & $0.01 \pm 0.01$ & nd \\
\hline C9YYE7 & SCAB_70561 & Pectinesterase & $0.30 \pm 0.04$ & $0.05 \pm 0.02$ & $0.03 \pm 0.03$ \\
\hline
\end{tabular}


Table 2 Proteins specifically produced by Streptomyces scabiei in the casein-suberin medium (Continued)

\begin{tabular}{|c|c|c|c|c|c|}
\hline C9YYE8 & SCAB_70571 & Pectinesterase & $0.24 \pm 0.08$ & $0.07 \pm 0.02$ & $0.04 \pm 0.03$ \\
\hline C9YYFO & SCAB_70591 & Pectate lyase & $0.36 \pm 0.09$ & $0.41 \pm 0.18$ & $0.29 \pm 0.30$ \\
\hline C9Z2Z4 & SCAB_73161 & Secreted protein & $0.36 \pm 0.06$ & $0.17 \pm 0.17$ & $0.04 \pm 0.06$ \\
\hline C9Z623 & SCAB_74681 & Licheninase & $0.07 \pm 0.07$ & $0.34 \pm 0.07$ & $0.27 \pm 0.11$ \\
\hline C9ZAZ8 & SCAB_77201 & Glycosyl hydrolase & $0.12 \pm 0.08$ & $0.95 \pm 0.25$ & $0.71 \pm 0.14$ \\
\hline C9ZB17 & SCAB_77391 & Glycosyl hydrolase & $0.01 \pm 0.02$ & $0.10 \pm 0.11$ & $0.06 \pm 0.06$ \\
\hline C9ZE74 & SCAB_79011 & Acetyl-xylan esterase & nd & $0.59 \pm 0.13$ & $0.52 \pm 0.09$ \\
\hline C9ZEB7 & SCAB_79481 & Xylanase A & $0.01 \pm 0.02$ & $0.02 \pm 0.03$ & $0.02 \pm 0.03$ \\
\hline C9ZFY5 & SCAB_79861 $1^{d}$ & Xylose isomerase & $0.04 \pm 0.01$ & $0.10 \pm 0.06$ & $0.11 \pm 0.05$ \\
\hline C9YU11 & SCAB_81841 & Glycosyl hydrolase & $0.13 \pm 0.11$ & $0.06 \pm 0.06$ & $0.01 \pm 0.01$ \\
\hline C9YU29 & SCAB_82021 & $\beta$-mannosidase & nd & $0.22 \pm 0.06$ & $0.24 \pm 0.07$ \\
\hline C9YU66 & SCAB_82411 & Pectate lyase & nd & $0.07 \pm 0.08$ & $0.06 \pm 0.07$ \\
\hline C9Z820 & SCAB_89901 ${ }^{d}$ & $\beta$-D-xylosidase & nd & $0.02 \pm 0.02$ & $0.02 \pm 0.02$ \\
\hline \multicolumn{6}{|c|}{ Amino acid metabolism } \\
\hline C9YVT3 & SCAB_6381 & Extracellular small neutral protease & $0.25 \pm 0.21$ & $0.08 \pm 0.11$ & $0.05 \pm 0.08$ \\
\hline C9YYP7 & SCAB_7651 & Zinc metalloprotease & $0.13 \pm 0.05$ & $0.04 \pm 0.04$ & $0.03 \pm 0.02$ \\
\hline C9YYX3 & SCAB_23151 ${ }^{d}$ & Arginine deaminase & nd & $0.00 \pm 0.01$ & $0.03 \pm 0.02$ \\
\hline C9Z238 & SCAB_25231 & Dihydrodipicolinate reductase & nd & $0.03 \pm 0.05$ & $0.01 \pm 0.03$ \\
\hline C9Z281 & SCAB_25691 ${ }^{d}$ & 4-aminobutyrate aminotransferase & $0.01 \pm 0.03$ & $0.04 \pm 0.04$ & $0.02 \pm 0.01$ \\
\hline C9Z5AO & SCAB_27061 ${ }^{d}$ & Ketol-acid reductoisomerase & $0.02 \pm 0.02$ & $0.02 \pm 0.02$ & $0.00 \pm 0.01$ \\
\hline C9YTF8 & SCAB_35641 ${ }^{d}$ & Serine hydroxymethyltransferase 4 & $0.02 \pm 0.02$ & nd & $0.01 \pm 0.01$ \\
\hline C9Z8U5 & SCAB_45071 $1^{d}$ & Zinc aminopeptidase & $0.04 \pm 0.01$ & $0.05 \pm 0.01$ & $0.07 \pm 0.03$ \\
\hline C9ZC37 & SCAB_46731 ${ }^{d}$ & Xaa-Pro aminopeptidase & $0.01 \pm 0.01$ & $0.06 \pm 0.04$ & $0.16 \pm 0.12$ \\
\hline C9Z7B6 & SCAB_59611 ${ }^{d}$ & Aminopeptidase N & $0.05 \pm 0.04$ & nd & nd \\
\hline C9Z4N7 & SCAB_87271 & Peptidase & $0.03 \pm 0.05$ & $0.10 \pm 0.13$ & $0.04 \pm 0.04$ \\
\hline \multicolumn{6}{|c|}{ Coenzyme metabolism } \\
\hline C9Z1Y4 & SCAB_9771 ${ }^{d}$ & Cobalamin biosynthesis protein & $0.02 \pm 0.02$ & $0.18 \pm 0.04$ & $0.12 \pm 0.07$ \\
\hline C9Z3M4 & SCAB_25861 ${ }^{d}$ & Aminotransferase & nd & $0.00 \pm 0.01$ & $0.03 \pm 0.03$ \\
\hline C9Z402 & SCAB_41841 & Aminotransferase & nd & $0.00 \pm 0.01$ & $0.01 \pm 0.03$ \\
\hline C9Z638 & SCAB_74841 ${ }^{d}$ & Pyridoxal biosynthesis lyase pdxS & $0.03 \pm 0.05$ & nd & nd \\
\hline C9Z7L0 & SCAB_75311 & S-adenosylmethionine synthase & nd & $0.01 \pm 0.02$ & $0.02 \pm 0.02$ \\
\hline \multicolumn{6}{|c|}{ Nucleotide metabolism } \\
\hline C9Z407 & SCAB_41891 ${ }^{d}$ & Adenylosuccinate synthetase & $0.01 \pm 0.03$ & nd & nd \\
\hline C9ZDR6 & SCAB_47861 ${ }^{d}$ & Phosphoribosylformylglycinamidine cyclo-ligase & $0.01 \pm 0.02$ & $0.00 \pm 0.01$ & $0.03 \pm 0.02$ \\
\hline C9Z7F8 & SCAB_60011 & Nucleoside diphosphate kinase & $0.02 \pm 0.04$ & $0.08 \pm 0.09$ & $0.09 \pm 0.13$ \\
\hline C9YVK8 & SCAB_68841 & 5' nucleotidase & $0.03 \pm 0.02$ & $0.15 \pm 0.09$ & $0.08 \pm 0.07$ \\
\hline \multicolumn{6}{|c|}{ Inorganic ion metabolism } \\
\hline C9YVE4 & SCAB_68191 ${ }^{d}$ & Alkaline phosphatase & $0.13 \pm 0.04$ & $0.06 \pm 0.04$ & $0.06 \pm 0.05$ \\
\hline C9ZB70 & SCAB_77971 & Alkaline phosphatase & $0.16 \pm 0.01$ & $0.19 \pm 0.07$ & $0.17 \pm 0.11$ \\
\hline \multicolumn{6}{|c|}{ General function prediction only } \\
\hline C9YSY7 & SCAB_4591 & Acyltransferases & $0.07 \pm 0.07$ & $0.02 \pm 0.03$ & nd \\
\hline C9YVP7 & SCAB_6001 ${ }^{d}$ & Feruloyl esterase & nd & $0.05 \pm 0.04$ & $0.06 \pm 0.06$ \\
\hline C9Z3D2 & SCAB_10131 & Glycosyl hydrolase & nd & $0.06 \pm 0.03$ & $0.06 \pm 0.03$ \\
\hline C9YT61 & SCAB_19541 & Carbohydrate esterase & $0.02 \pm 0.03$ & $0.05 \pm 0.03$ & $0.01 \pm 0.02$ \\
\hline C9Z233 & SCAB_25181 ${ }^{d}$ & B lactamase & $0.01 \pm 0.01$ & $0.03 \pm 0.04$ & $0.05 \pm 0.03$ \\
\hline
\end{tabular}


Table 2 Proteins specifically produced by Streptomyces scabiei in the casein-suberin medium (Continued)

\begin{tabular}{|c|c|c|c|c|c|}
\hline C9Z6S2 & SCAB_27611 & Phage tail sheath protein $\mathrm{FI}$ & nd & $0.03 \pm 0.01$ & $0.09 \pm 0.05$ \\
\hline C9Z8SO & SCAB_44821 ${ }^{d}$ & Phosphatase & $0.03 \pm 0.05$ & $0.00 \pm 0.01$ & nd \\
\hline C97994 & SCAB_61611 $1^{d}$ & Protease & $0.05 \pm 0.04$ & $0.14 \pm 0.03$ & $0.03 \pm 0.03$ \\
\hline C9ZAQ7 & SCAB_61831 ${ }^{d}$ & Metalloendopeptidase & nd & nd & $0.03 \pm 0.03$ \\
\hline C9ZAU3 & SCAB_62211 & Phosphatase & nd & $0.11 \pm 0.05$ & $0.17 \pm 0.07$ \\
\hline C9ZDW7 & SCAB_63921 ${ }^{d}$ & Dehydratase & nd & $0.04 \pm 0.05$ & $0.07 \pm 0.03$ \\
\hline C9ZHBO & SCAB_66321 ${ }^{d}$ & F420-dependent NADP reductase & nd & $0.02 \pm 0.03$ & $0.05 \pm 0.05$ \\
\hline C9ZB18 & SCAB_77401 & Glycosyl hydrolase & nd & $0.06 \pm 0.03$ & $0.05 \pm 0.04$ \\
\hline C9ZCL9 & SCAB_78431 & Tripeptidylaminopeptidase & $0.13 \pm 0.01$ & $0.14 \pm 0.04$ & $0.14 \pm 0.11$ \\
\hline C9ZEA8 & SCAB_79391 & Glycosyl hydrolase & nd & $0.13 \pm 0.07$ & $0.11 \pm 0.09$ \\
\hline C9ZEC6 & SCAB_79571 & Glycosyl hydrolase & nd & $0.03 \pm 0.03$ & $0.01 \pm 0.02$ \\
\hline C9YYG1 & SCAB_83671 ${ }^{d}$ & Acetyl esterase & nd & $0.00 \pm 0.01$ & $0.02 \pm 0.05$ \\
\hline C9ZO47 & SCAB_84861 & Amidase & $0.21 \pm 0.05$ & $0.11 \pm 0.03$ & $0.06 \pm 0.06$ \\
\hline \multicolumn{6}{|c|}{ Unknown function } \\
\hline C9Z6Q2 & SCAB_12841 & & $0.44 \pm 0.12$ & $0.70 \pm 0.25$ & $0.59 \pm 0.17$ \\
\hline C9ZBK5 & SCAB_15581 ${ }^{d}$ & & $0.04 \pm 0.04$ & $0.03 \pm 0.02$ & $0.03 \pm 0.03$ \\
\hline C9YVU0 & SCAB_20641 & & $0.07 \pm 0.04$ & $0.34 \pm 0.09$ & $0.38 \pm 0.11$ \\
\hline C9ZOX8 & SCAB_40131 & & $0.28 \pm 0.13$ & $0.14 \pm 0.05$ & $0.07 \pm 0.03$ \\
\hline C9Z5E6 & SCAB_42301 ${ }^{d}$ & & nd & $0.03 \pm 0.06$ & $0.03 \pm 0.06$ \\
\hline C9ZGX5 & SCAB_49501 & & $0.06 \pm 0.06$ & nd & nd \\
\hline C9YV55 & SCAB_52141 ${ }^{d}$ & & $0.02 \pm 0.03$ & $0.03 \pm 0.03$ & $0.08 \pm 0.09$ \\
\hline C9Z1G8 & SCAB_72441 & & $0.17 \pm 0.06$ & $0.27 \pm 0.09$ & $0.32 \pm 0.10$ \\
\hline C9Z609 & SCAB_74541 & & $0.12 \pm 0.14$ & nd & $0.02 \pm 0.04$ \\
\hline C9ZG06 & SCAB_80071 & & $0.02 \pm 0.03$ & nd & nd \\
\hline
\end{tabular}

${ }^{\mathrm{a}}$ Uniprot accession number; ${ }^{\mathrm{b}}$ Data are the mean of three replicates; ${ }^{\mathrm{c}}$ nd: not detected; ${ }^{\mathrm{d}}$ Protein with intracellular localisation prediction.

intracellular proteins in CSM may reflect contamination of the secretome by intracellular content of lysed cells. Most of the proteins included in translational, ribosomal structure and biogenesis, coenzyme metabolism and nucleotide metabolism classes were predicted to be localized in the cytoplasm and were found predominantly in samples grown in CSM (Table 3). Higher levels of lysis in CSM may be due to the fact that monomers associated with the suberin structure act as membrane perturbants [15]. Furthermore, suberin has been shown to increase membrane fluidity in S. scabiei [6].

Although both CM and CSM contain casein as carbon and nitrogen sources, 124 different proteins were specifically detected in the CM supernatants, indicating that the presence of suberin might repress expression of several genes (Additional file 2: Table S2). As reported in other proteomic studies [2,3], a non-negligible number of detected proteins have unknown functions and surprisingly, several proteins of unknown function were associated with growth in CM (Table 3). Proteins included in posttranscriptional modification, protein turnover and chaperones and in cell envelope biogenesis classes were also found in higher proportion in CM-grown samples
(Table 3). It has been reported that suberin induces a thickening of the cell wall [6] and the differential production of proteins involved in cell envelope biogenesis suggest that both cell wall structure and composition of S. scabiei may differ depending on the culture media.

Among the 246 proteins associated with both culture media, $41 \%$ of them were 5 -fold more abundant in CSM after 1, 3 or 5 days of growth (Table 1). A total of 139 proteins were specifically detected in CSM supernatants indicating that the presence of suberin triggers the expression of a number of genes (Table 2). Several of the proteins found in higher proportion in the presence of suberin were classified into the carbohydrate metabolism class and two functional groups of proteins (degradation of aromatic compounds and secondary metabolites biosynthesis, transport and catabolism) were exclusively associated with growth in CSM (Table 3).

In addition, a factor $\mathrm{C}$-like morphological differentiation protein (C9Z7Z7) was more abundant and was detected at an earlier time point in the S. scabiei secretome when the bacterium was grown in the presence of suberin. Promotion of differentiation by suberin in the genus Streptomyces has been previously reported [6]. This promotion might be 
Table 3 Distribution of Streptomyces scabiei proteins into functional groups

\begin{tabular}{|c|c|c|c|}
\hline \multirow[t]{2}{*}{ Class of proteins } & \multicolumn{3}{|c|}{ Number of proteins } \\
\hline & In CM only & Overproduced in $\mathrm{CSM}^{\mathrm{a}}$ & In CSM only \\
\hline Translational, ribosomal structure and biogenesis & $2^{b}$ & $17^{\mathrm{b}}$ & $23^{\mathrm{b}}$ \\
\hline Transcription & 2 & $1^{\mathrm{b}}$ & $3^{\mathrm{b}}$ \\
\hline Posttranslational modification, protein turnover, chaperone & 11 & 0 & $2^{\mathrm{b}}$ \\
\hline Cell wall/membrane/envelope biogenesis & 14 & 2 & $4^{\mathrm{b}}$ \\
\hline Signal transduction mechanisms & $3^{b}$ & 0 & $1^{\mathrm{b}}$ \\
\hline Secretion & 3 & 0 & 0 \\
\hline Defense mechanism and virulence & 3 & 2 & $5^{b}$ \\
\hline Secondary metabolites biosynthesis, transport and catabolism & 0 & 0 & 4 \\
\hline Differentiation & 1 & 1 & 0 \\
\hline Energy production and conversion & 4 & $4^{\mathrm{b}}$ & $2^{\mathrm{b}}$ \\
\hline Lipid metabolism & 1 & 3 & $8^{b}$ \\
\hline Degradation of aromatic compounds & 0 & 0 & 1 \\
\hline Carbohydrate metabolism & 5 & 45 & 36 \\
\hline Amino acid metabolism & 14 & 13 & $11^{\mathrm{b}}$ \\
\hline Coenzyme metabolism & $1^{\mathrm{b}}$ & 0 & 5 \\
\hline Nucleotide metabolism & $1^{\mathrm{b}}$ & 1 & $4^{b}$ \\
\hline Inorganic ion metabolism & 3 & 1 & 2 \\
\hline General function prediction only & 9 & 3 & 18 \\
\hline Unknown function & 47 & 8 & 10 \\
\hline
\end{tabular}

aprotein with a spectral counting/MW 5-fold greater in CSM than in CM; ${ }^{\mathrm{b}}$ Most or all proteins have a predicted intracellular localisation.

at least partly due to a higher concentration of the secreted factor $\mathrm{C}$, which is known to play a role in morphological differentiation and to restore wild-type developmental gene expression to an A-factor non-producing mutant of Streptomyces griseus [16]. Furthermore, a factor C null mutant of strain Streptomyces albidoflavus, a common scabinducing strain, exhibited a bald phenotype and appeared less pathogenic than the wild-type bacteria [17]. Suberin seemed also to promote the initiation of the secondary metabolism that triggered the production of thaxtomin A, a phytotoxin essential for S. scabiei pathogenicity [5].

\section{Abundance of extracellular proteins associated with carbohydrate metabolism in suberin-containing medium} Out of 240 proteins overproduced or exclusively produced in the presence of suberin, 81 (33\%) were involved in carbohydrate metabolism (Tables 1 and 2) and 49 of

Table 4 Proportion of predicted extracellular proteins in the secretome Streptomyces scabiei grown in CM of CSM

\begin{tabular}{lcc}
\hline Cultivation & Proportion of predicted extracellular proteins (\%) \\
\cline { 2 - 3 } time & CM & CSM \\
\hline 1-day-old culture & 73 & 68 \\
3-day-old culture & 87 & 65 \\
5-day-old culture & 88 & 66 \\
\hline
\end{tabular}

these were identified as glycosyl hydrolases $(\mathrm{GH})$ using CAZy classification (Table 3). Two proteins (C9ZE95 and $\mathrm{C} 9 \mathrm{Z} 5 \mathrm{~L} 1$ ) in this class figured among the ten most abundant proteins in the 24-h CSM supernatant. After 5 days of incubation, these two proteins as well as three other proteins of the same class (C9ZD50, C9ZEP9 and C9ZE94) were included in the ten most highly represented proteins in the CSM supernatant. In contrast, no proteins belonging to the carbohydrate metabolism class appeared among the ten most abundant proteins in the $\mathrm{CM}$ at any sampling time. This abundance of glycosyl hydrolases in CSM was unexpected considering that this culture medium was not supplemented with polysaccharides. Nevertheless, some of the putative glycosyl hydrolases present in the supernatant were active, since CSM supernatants exhibited cellulase, xylanase and licheninase activities (Table 5).

Production of glycosyl hydrolases in the presence of suberin may be due to the presence of sugar contaminants in suberin. The polymer is anchored in the plant cell wall and is tightly associated with other cell wall components such as polysaccharides [10]. Enzymatic and extractive protocols have been optimized to remove around $95 \%$ of the unsuberized cell walls and waxes from suberized potato periderm [18]. Nevertheless, cell wall polysaccharides are covalently attached to the polyester biopolymer and could thus be inaccessible to enzymes used to purify 
Table 5 Enzymatic activities $(\mathrm{mU} / \mathrm{ml})^{\mathrm{a}}$ associated with supernatants of Streptomyces scabiei grown in CM or CSM

\begin{tabular}{|c|c|c|c|c|c|c|}
\hline & \multicolumn{2}{|c|}{ Xylanase } & \multicolumn{2}{|c|}{ Cellulase } & \multicolumn{2}{|c|}{ Licheninase } \\
\hline & $\mathrm{CM}$ & CSM & $\mathrm{CM}$ & CSM & CM & CSM \\
\hline 1-day-old culture & 0 & $30.1 \pm 7.4$ & 0 & $12.2 \pm 2.1$ & $5.7 \pm 2.7$ & $30.8 \pm 23.6$ \\
\hline 3-day-old culture & 0 & $314.0 \pm 11.6$ & 0 & $26.3 \pm 4.3$ & $5.1 \pm 3.8$ & $50.2 \pm 2.5$ \\
\hline 5-day-old culture & $9.7 \pm 2.5$ & $372.0 \pm 9.0$ & $7.7 \pm 0.3$ & $32.8 \pm 2.1$ & $64.1 \pm 4.9$ & $116.0 \pm 4.5$ \\
\hline
\end{tabular}

${ }^{\text {aData }}$ are the mean of three replicates.

suberin. When grown in the presence of suberin, contaminating cell wall polysaccharides represent a higher carbon energy supply for the bacteria than the aliphatic and aromatic fractions of suberin, explaining the importance of this group of enzymes in S. scabiei secretome.

A set of enzymes possibly involved in xylan catabolism were specific to the suberin-containing medium or were found in higher proportion in the presence of suberin. A putative xylanase A (C9ZE95) was among the most abundant proteins detected in suberin-containing medium at all sampling times and its abundance was between 20 to 26 times higher than in CM samples (Table 1). Complete hydrolysis of xylan requires xylanases such as endo- $\beta-1$, 4-xylanases, $\beta$-xylosidase and other enzymes that cleave side chain sugars from the xylan backbone, such as $\alpha$ arabinofuranosidases and acetyl esterases, for example. Most xylanases found in this study belong to glycoside hydrolase families GH5, GH8, GH10, GH11, GH30 and GH43 (CAZy classification [19]).

Some of the proteins detected only in CSM and included in the carbohydrate metabolism class were putative polysaccharide lyases (C9YU66, C9YYE6, C9YYF0, C9Z574 and C9Z725) or carbohydrate esterases (C9YVN4, C9YVP5, C9YYE7, C9YYE8 and C9ZE74). Among them, proteins C9YYE6, C9YYE7 and C9YYE8, encoded by three adjacent genes, were predicted to belong to an operon of four genes (http://www.microbesonline.org/operons/gnc680198.html) and are probably involved in pectin degradation. The fourth gene of the operon encodes for the lipolytic enzyme C9YYE5, which was also only detected in suberincontaining medium.

In addition to enzymes involved in xylan and pectin degradation, other types of polysaccharide-degrading enzymes were detected specifically in CSM: cellulases (C9YVP5, C9YW88 and C9ZEQ1), a putative licheninase (C9Z623) and several enzymes involved in the hydrolysis of hemicellulose compounds. Glycosyl hydrolase activity in CS and CSM supernatants has been assayed on cellulose, xylan and lichenin and our experiments revealed that CSM supernatants possessed higher cellulase, xylanase and licheninase activity (Table 5). Furthermore, addition of a small amount of suberin to S. scabiei culture media containing carboxymethyl cellulose or xylan as the main carbon source considerably increased the cellulase and xylanase activities, respectively (unpublished data). Given that the amount of suberin added in the culture media is relatively small, the increase in enzymatic activity is unlikely to be attributable to contamination of the suberin polymer with cellulose or xylan. This increase might be due to the secretion of glycosyl hydrolases specifically induced by the presence of suberin or to an overproduction of extracellular enzymes caused by the addition of suberin. Phenolic suberin compounds might be partly responsible for the high glycosyl hydrolase activity since various phenolic compounds such as gallic acid, tannic acid, maleic acid and salicylic acid were shown to induce expression of various genes encoding cellulases [20]. The promotion of secondary metabolism by suberin [6] could also explain this overproduction as the A-factor regulon includes many extracellular glycosyl hydrolases in S. griseus [21].

Topochemical studies have shown that a part of the suberin polyaromatic domain is located in the primary and tertiary cell walls [10]. Polyaromatic compounds from suberin are thus associated with polysaccharidetype glycosides but the nature of their covalent link remains speculative [10]. The fact that several secreted carbohydrate esterases identified in this study belonged to carbohydrate esterase families CE1, CE2, CE7 and CE12 (Table 3) that include acetyl xylan esterases and pectin acetyl esterases suggests that the polyaromatic fraction of suberin, like lignin, another polyaromatic structure, is linked to cell wall polysaccharides by ester bonds [22].

\section{Identification of extracellular proteins possibly involved in suberin degradation}

The main purpose of this work was to identify extracellular proteins produced in the presence of suberin, the main constituent of potato periderm. Suberin is an insoluble lipidic biopolymer [10] and the mechanisms responsible for its degradation are poorly understood [11]. Nevertheless, some authors have suggested that actinobacteria, including S. scabiei $[6,12]$, might be involved in the degradation of the aliphatic portion of suberin.

Interestingly, most proteins of the lipid metabolism class have been detected only in the supernatant of CSM (C9YTK3, C9YYE5, C9YY49, C9ZD66, C9ZGV4, C9Z6Y2, 
C9Z7Q3 and C9Z776) or were more abundant in this medium (C9ZCR0, C9Z5Z2 and C9Z707). Four of these proteins, a protein from the esterase-lipase family (C9YTK3), a lipolytic enzyme (C9YYE5), a glycerophosphoryl diester phosphodiesterase (C9Z5Z2) and a putative sphingolipid ceramide $\mathrm{N}$-deacylase (C9ZCR0) have a predicted extracellular localisation and could thus be directly involved in suberin degradation.

Current models for suberin structure postulate that approximately $25 \%$ of the suberin structure can be depolymerized by ester cleavage reactions [8]. The predicted function of C9YTK3 and C9YYE5 suggests that these proteins could hydrolyze esters of fatty acids. They could thus be of importance in attacking the aliphatic structure of suberin or in liberating glycerol from fatty acids. Expression of the corresponding four genes was compared in CM and CSM (Table 6). The esterase/lipase gene was only slightly overexpressed in the presence of suberin while the gene coding for the lipolytic enzyme was more than ten-fold overexpressed after 2 to 5 days of incubation in the presence of suberin. Although suberin induced a considerable increase in expression of the gene encoding the lipolytic enzyme, the corresponding protein was present at a low concentration in CSM and was detected only in a 1-day-old culture medium. Komeil et al. (2013) [12] identified sub1, a potential suberinase gene in S. scabiei genome. The sub1 gene was specifically expressed in the presence of suberin but the Sub1 protein has never been detected in the S. scabiei secretome. Because the aliphatic constituents of suberin act as cell membrane peturbants [15], a low production of lipolytic enzymes might be required for bacterial survival.

The C9Z5Z2 protein is a putative glycerophosphoryl diester phosphodiesterase involved in metabolism of glycerol and lipids and the corresponding gene was overexpressed in the first days of growth in the presence of suberin (Table 6). Glycerol has been reported to be covalently bound to the aliphatic and aromatic fractions of potato suberin, allowing the formation of a three-dimensional crosslinked network [8]. During its interaction with potato tubers, S. scabiei may thus release glycerol from suberin and use this compound as a carbon source. Furthermore, suberin depolymerisation by methanolysis was shown to release a set of glycerol-derived dimeric and trimeric esters [10]. Among glycerol esters, monoacylglycerols of $\alpha, \omega$-diacids and of $\omega$-hydroxyacids were found in high concentrations. The putative sphingolipid ceramide $\mathrm{N}$-deacylase C9ZCR0 that is overproduced in the presence of suberin might thus remove acyl groups from monoacylglycerol present in the polymer. C9ZCR0 as well as C9YSS1, a putative $\alpha$-galactosidase, are related to enzymes involved in sphingolipid degradation (based on KEGG pathway database [23]) and like suberin, sphingolipids also contain long chain fatty acids. The genes encoding C9ZCR0 and C9YSS1 were overexpressed in the presence of suberin (Table 6).

Esterases exhibit activity on a wide range of substrates [24]. As such, esterases not specifically produced in the presence of suberin, for instance C9ZG71 (esterase A) and C9Z6Y6 (cholesterol esterase), might nevertheless play a role in suberin degradation (Additional file 1: Table S1). In a previous study, esterase A was detected in $S$. scabiei suberin-containing culture medium [12]. C9Z6Y6 is a widespread cholesterol esterase belonging to the lipase/ esterase family [25] and it is able to hydrolyze fatty acid esters of cholesterols. Cholesterol esterases have also been characterized in bacteria such as Pseudomonas aeruginosa [26], Acinetobacter sp. [27] and Streptomyces spp. [28], suggesting that these bacterial enzymes do not use cholesterol as a specific substrate.

Apart from lipid metabolism proteins, accessory proteins may also actively participate in the breakdown of suberin architecture. That is the case for two feruloyl esterases (C9ZE96 and C9YVP7) included in the general function class (Tables 1 and 2). Feruloyl esterase C9ZE96 was overproduced in the presence of suberin while C9YVP7 was only found in CSM. Both feruloyl esterase genes were clearly overexpressed in the presence of suberin (between

Table 6 Effect of suberin on Streptomyces scabiei gene expression

\begin{tabular}{|c|c|c|c|c|c|c|}
\hline \multirow{2}{*}{$\begin{array}{l}\text { Gene } \\
\text { assignation }\end{array}$} & \multirow{2}{*}{$\begin{array}{l}\text { Protein } \\
\text { assignation }\end{array}$} & \multirow[t]{2}{*}{ Putative function } & \multicolumn{4}{|c|}{ Relative gene expression $^{a}$} \\
\hline & & & Day 2 & Day 3 & Day 4 & Day 5 \\
\hline$\overline{S C A B \_3891}$ & C9YSS1 & a-galactosidase & $7.3 \pm 3.5^{b}$ & $6.3 \pm 3.2^{b}$ & $3.4 \pm 1.0^{b}$ & $3.4 \pm 1.1^{b}$ \\
\hline SCAB_6001 & C9YVP7 & Feruloyl esterase & $29.6 \pm 14.8^{b}$ & $74.0 \pm 24.0^{b}$ & $78.0 \pm 23.6^{b}$ & $159.3 \pm 14.3^{b}$ \\
\hline SCAB_51091 & C9YTK3 & Esterase-lipase & $1.8 \pm 0.6^{\mathrm{b}}$ & $1.9 \pm 0.5^{b}$ & $0.8 \pm 0.1$ & $1.5 \pm 0.4$ \\
\hline SCAB_57301 & C9Z2P6 & 3-oxo-5.6-dehydrosuberyl-CoA semialdehyde dehydrogenase & $1.7 \pm 0.6^{\mathrm{b}}$ & $2.3 \pm 1.2$ & $1.2 \pm 0.6$ & $1.0 \pm 0.3$ \\
\hline SCAB_70541 & C9YYE5 & Lipolytic enzyme & $3.6 \pm 1.3^{b}$ & $9.4 \pm 4.1^{b}$ & $6.5 \pm 0.9^{b}$ & $12.9 \pm 1.3^{b}$ \\
\hline SCAB_74351 & C9Z5Z2 & Glycerophosphoryl diester phosphodiesterase & $2.0 \pm 0.5^{b}$ & $3.6 \pm 0.9^{b}$ & $1.2 \pm 0.5$ & $1.2 \pm 0.1$ \\
\hline SCAB_78851 & C9ZCRO & Sphingolipid ceramide N-deacylase & $1.2 \pm 0.4$ & $4.6 \pm 1.7^{b}$ & $1.8 \pm 0.2^{\mathrm{b}}$ & $1.3 \pm 0.3$ \\
\hline SCAB_79261 & C9ZE96 & Feruloyl esterase & $298.3 \pm 184.3^{b}$ & $298.6 \pm 81.0^{b}$ & $301.0 \pm 73.6^{b}$ & $342.0 \pm 46.3^{b}$ \\
\hline
\end{tabular}

${ }^{\mathrm{a}}$ Data are the mean of four replicates; ${ }^{\mathrm{b}}$ Gene expression was significantly different between growth conditions. 
30 to 340 times from days 2 to 5 , Table 6). The potato suberin feruloyl transferase FHT, which catalyzes the transfer of ferulic acid to $\omega$-hydroxyfatty acids and fatty alcohols, was shown to be essential for periderm maturation [29], and potatoes deficient in FHT display a periderm that is over ten times more permeable to water compared to wild-type potatoes [30]. Since suberin structure models suggest that ferulate links the aliphatic fraction to the aromatic fractions of suberin [10], feruloyl esterases may possibly disassociate the two suberin domains, making the substrate more accessible to hydrophilic enzymes. Alternatively or concomitantly, these enzymes may, as in some fungi, be responsible for cleaving ester links between polysaccharides such as xylan or pectin and ferulic acid, an aromatic residue [31].

Bacterial degradation of suberin aromatic fractions has, to our knowledge, never been documented. Only one extracellular protein in CSM could be linked to the degradation of aromatic compounds (Table 2). C9Z2P6 is a putative 3-oxo-5,6-dehydrosuberyl-CoA semialdehyde dehydrogenase that belongs to the phenylacetate catabolic pathway of aromatic compounds [32]. The gene encoding C9Z2P6 was overexpressed approximately 2-fold in the presence of suberin after the first day of growth (Table 6).

Suberin is a determining factor in the outcome of S. scabiei-potato tuber interaction. Suberin induces the onset of virulence mechanisms of S. scabiei [5]. In potato tuber, suberin biosynthesis is induced in response of S. scabiei infection offering a physical protection to pathogen entry [33]. A recent study has effectively shown that enhanced suberin production in potato tubers provides protection against common scab [34]. Degradation of suberin by $S$. scabiei may contribute to nutrient acquisition during both parasitic and saprophytic modes of life. Nevertheless, elucidating the involvement of suberin in the different steps of bacterial infection is still difficult as the suberin degradation process remains highly speculative.

\section{Conclusions}

This study has allowed the identification of various extracellular enzymes that could be involved in suberin degradation (lipolytic enzymes, deacylases, feruloyl esterases) or in degradation of other potato cell wall constituents. Cellulases, xylanases or pectinases associated with S. scabiei have never been characterized although their role in pathogenicity may be of importance. Presence in S. scabiei secretome of numerous enzymes implicated in carbohydrate metabolism is unlikely to be attributable to sugar contamination of the suberin polymer, suberin rather appears to stimulate the production of such enzymes. Further study on these proteins could provide a new source of knowledge to unravel the molecular basis of $S$. scabiei virulence mechanisms.

\section{Methods}

\section{Bacteria, growth conditions and inoculation}

The pathogenic Streptomyces scabiei strain EF-35 was isolated from a common scab lesion from a potato tuber collected in Canada [2]. Bacterial inoculum was prepared as follows. Approximately $10^{8}$ spores were added to $25 \mathrm{~mL}$ of yeast malt extract (YME, $4 \mathrm{~g} / \mathrm{L}$ of glucose, $4 \mathrm{~g} / \mathrm{L}$ of yeast extract and $10 \mathrm{~g} / \mathrm{L}$ of malt extract; BD, Detroit, MI, USA) and incubated with shaking $(250 \mathrm{r} / \mathrm{min})$ for $48 \mathrm{~h}$ at $30^{\circ} \mathrm{C}$. The bacterial culture was then centrifuged $(2500 \times g)$ for $5 \mathrm{~min}$ and the supernatant discarded. Bacterial pellets were subsequently resuspended in 5 volumes of $0.85 \%$ $\mathrm{NaCl}$. In all experiments, an inoculum of $200 \mu \mathrm{L}$ was transferred to $50 \mathrm{~mL}$ of minimal medium supplemented with $0.1 \%$ suberin and $0.05 \%$ casein hydrolysate (Sigma, St. Louis, MO, USA), or casein hydrolysate only. Suberin was extracted from potato tubers according to Lerat et al. (2012) [6]. Three culture replicates for each medium were incubated with shaking $(250 \mathrm{r} / \mathrm{min})$ at $30^{\circ} \mathrm{C}$ for 1,3 or 5 days.

\section{Extracellular protein extraction}

The protein concentrations of S. scabiei supernatant samples were measured according to Bradford (1976) [35] with bovine serum albumin used as a standard. The absorbance of the solution at $595 \mathrm{~nm}$ was measured after $5 \mathrm{~min}$ of incubation at room temperature. A standard curve prepared with known concentrations of bovine serum albumin was used to determine the sample protein concentrations.

Extracellular proteins were recovered by centrifuging bacterial cultures at $2500 \times g$ for $15 \mathrm{~min}$ at $4^{\circ} \mathrm{C}$. Proteins in the supernatants were concentrated to a final volume of $500 \mu \mathrm{L}$ using Amicon ${ }^{\odot}$ Ultra-15 Centrifugal Filters-3 K followed by addition of 5 volumes of $100 \%$ pre-chilled acetone. After $3 \mathrm{~h}$ of incubation at $20^{\circ} \mathrm{C}$, proteins were recovered by centrifugation $\left(14000 \times g, 20 \mathrm{~min}, 4^{\circ} \mathrm{C}\right)$. Protein pellets were air dried and resuspended in $80 \mu \mathrm{L}$ of a buffer composed of $8 \mathrm{M}$ urea, 2\% (w/v) CHAPS, 2\% (v/v) IPG buffer pH 4-7 (GE Healthcare, Buckinghamshire, UK), 18.15 mM DTT and 0.002\% bromophenol blue stock solution in $50 \mathrm{mM}$ Tris-base. A centrifugation $(14000 \times g)$ was then carried out for $5 \mathrm{~min}$ at $4^{\circ} \mathrm{C}$ to remove insoluble material.

\section{Enzymatic assays}

Cellulase, licheninase and xylanase activities in S. scabiei culture supernatants were determined according to Lever (1972) [36]. Briefly, each supernatant sample (100 $\mu \mathrm{L})$ was added to $400 \mu \mathrm{L}$ of $0.1 \%(\mathrm{w} / \mathrm{v})$ of carboxymethylcellulose $(\mathrm{CMC})$ or $0.1 \%(\mathrm{w} / \mathrm{v})$ xylan or $0.1 \%(\mathrm{w} / \mathrm{v})$ lichenin and the mixtures were incubated at $50^{\circ} \mathrm{C}$ for $30 \mathrm{~min}$. The enzymatic reaction was stopped by adding $1 \mathrm{~mL}$ of $\mathrm{PAHBAH}$ solution $\left(\mathrm{NaOH} 5 \mathrm{M}\right.$, trisodium citrate $0.5 \mathrm{M}, \mathrm{NaSO}_{3}$ 
$1 \mathrm{M}, \mathrm{CaCl}_{2} 0.2 \mathrm{M}$ and $10 \mathrm{~g} / \mathrm{L}$ of p-hydroxy benzoic acid hydrazide). Samples were subsequently boiled for $30 \mathrm{~min}$ to allow color development. The vials were then placed on ice for $5 \mathrm{~min}$. Insoluble material was eliminated by centrifugation $(14000 \times g, 5 \mathrm{~min})$. The same procedure was carried out for the blank control samples, but PAHBAH solution was added to the supernatant sample before incubation at $50^{\circ} \mathrm{C}$. The optical density of each test and blank samples was determined at $405 \mathrm{~nm}$ with a spectrophotometer (Ultrospec 3000-Biochrom). One unit of enzyme activity was defined as the amount of enzyme releasing $1 \mu \mathrm{mol}$ of reducing sugar per min.

\section{One-dimensional gel electrophoresis}

Extracellular proteins were subjected to sodium dodecyl sulfate-polyacrylamide gel electrophoresis (10\% SDSPAGE). Each protein sample consisted of $9 \mu \mathrm{L}$ of concentrated proteins and $3 \mu \mathrm{L}$ of loading buffer $(0.5 \mathrm{M}$ Tris $-\mathrm{HCl}$, $\mathrm{pH} 6.8,50 \%[\mathrm{v} / \mathrm{v}]$ glycerol, $10 \%[\mathrm{w} / \mathrm{v}]$ SDS, 5\% [v/v] $\beta$-mercaptoethanol, and $0.05 \%$ [w/v] bromophenol blue) in a $12 \mu \mathrm{L}$ final volume. The proteins were denaturated by incubating the samples at $100^{\circ} \mathrm{C}$ for $5 \mathrm{~min}$ before electrophoresis. Electrophoresis was carried out using a BioRad Mini Protean ${ }^{\circ}$ Tetra Cell (Bio-Rad, Hercules, CA, USA) at $100 \mathrm{~V}$ for $60 \mathrm{~min}$ with a 3-(N-morpholino) propanesulfonic acid (MOPS) running buffer containing $50 \mathrm{mM}$ MOPS, $50 \mathrm{mM}$ Tris, $0.1 \%$ SDS, and $0.03 \%(\mathrm{w} / \mathrm{v})$ EDTA. The protein molecular weight markers used were PageRuler ${ }^{\text {tm }}$ Prestained Protein Ladder (Thermo Scientific, Ottawa, Canada). Proteins were stained with Coomassie brilliant blue R-250 (Bio-Rad) [2]. Individual protein bands were excised from the SDS-PAGE gels and separated into two groups according to protein band intensity (low and high intensity).

\section{In-gel digestion of proteins and mass spectrometry}

In-gel digestion and mass spectrometry were carried out at the Proteomics Platform of the Quebec Genomics Center (Quebec City, Canada). Proteins were in-gel digested with trypsin using a MassPrep liquid handling robot (Waters, Milford, MA, USA) according to Shevchenko et al. (1996) [37] with modifications as suggested by Havliš et al. (2003) [38]. Briefly, the excised slices were destained in a solution containing $50 \mu \mathrm{L}$ of $50 \mathrm{mM}$ ammonium bicarbonate and $50 \mu \mathrm{L}$ acetonitrile, washed once with $50 \mu \mathrm{L}$ of $100 \mathrm{mM}$ ammonium bicarbonate and dehydrated with $50 \mu \mathrm{L}$ of acetonitrile. The proteins were in-gel reduced with $10 \mathrm{mM}$ DTT for $30 \mathrm{~min}$ at $37^{\circ} \mathrm{C}$ and alkylated with $55 \mathrm{mM}$ iodoacetamide for $30 \mathrm{~min}$ at room temperature. Proteins were digested with $105 \mathrm{mM}$ sequencing grade modified porcine trypsin (Promega, Madison, WI, USA) at $58^{\circ} \mathrm{C}$ for $1 \mathrm{~h}$. Digestion products were first extracted with a solution of $1 \%$ formic acid and $2 \%$ acetonitrile, then with a solution of $1 \%$ formic acid and 50\% acetonitrile. The recovered peptide extracts were pooled, dried in a vacuum centrifuge and resuspended in $5 \mu \mathrm{L}$ of $0.1 \%$ formic acid. Peptides were separated in a PicoFrit column BioBasic C18, $10 \mathrm{~cm} \times$ $0.075 \mathrm{~mm}$ internal diameter (New Objective, Woburn, MA, USA) with a linear gradient ( $2 \%$ to $50 \%$ acetonitrile containing $0.1 \%$ formic acid) in $30 \mathrm{~min}$ at $200 \mathrm{nl} / \mathrm{min}$. The samples were then transferred on a Thermo Surveyor MS pump connected to a LTQ linear ion trap mass spectrometer (Thermo Electron, San Jose, CA, USA) equipped with a nanoelectrospray ion source (Thermo Electron). Xcalibure 2.0 software was used for mass spectra acquisition. Each full-scan mass spectrum $(400-2000 \mathrm{~m} / \mathrm{z})$ was followed by collision-induced dissociation of the seven most intense ions (30 s dynamic exclusion duration and $35 \%$ relative collisional fragmentation energy).

\section{Interpretation of tandem MS spectra}

All MS/MS spectra were analysed for peptide identification using Mascot (Matrix Science, London, UK; version 2.2.0). Mascot parameters were set to search the Streptomyces Uniref100 database, based on trypsin digestion, with a fragment ion mass tolerance of $0.5 \mathrm{Da}$ and a parent ion tolerance of 2.0 Da. The following search criteria were used: two missed cleavages were allowed, iodoacetamide derivative of cysteine was specified as a fixed modification and oxidation of methionine was specified as a variable modification. Peptide tolerance was $2.0 \mathrm{Da}$ for the precursor and 0.5 Da for MS/MS. Score Mascot corresponded to $10 \times \log (\mathrm{P})$, where $\mathrm{P}$ is the probability that the observed match with a given MS/MS spectra is a random event.

\section{Protein label-free spectral counting, identification and characterisation}

Scaffold software program (version Scaffold 4.0.5, Proteome Software, Portland, OR, USA) was used to group peptides into protein and sum spectral counts for each protein. Protein identifications were accepted if they obtained a $99 \%$ minimum protein ID probability and presented a minimum of two unique peptides in which the cut offs for peptide thresholds were $90 \%$. Identified proteins were re-annotated and queried against GenBank sequence databases. Protein functions and assignment to functional groups were predicted using tools such as PRIAM [39], CAZy database [19], KEGG resources [40], COG database [41] and MicrobesOnLine resources [42]. Cellular localization of the proteins was predicted by Phobius [43], SignalP 4.1 [44], SecretomeP [45], TatP [46] and Tatfind 1.4 [47] analysis.

\section{Analysis of relative gene expression}

The expression of genes SCAB_6001, SCAB_51091, SCAB_70541, SCAB_74351, SCAB_78851, SCAB_79251 and SCAB_84861 was monitored over time. S. scabiei EF-35 was grown for 5 days in casein-containing 
minimal medium, supplemented or not with suberin (see above for details, four replicates per medium). From 2 to 5 days after inoculation, bacterial cultures were subsampled $(10 \mathrm{~mL})$ every $24 \mathrm{~h}$ to extract total RNA. Sampling procedures, RNA extraction and cDNA synthesis were carried out as in Lerat et al. (2010) [5]. Real-time RT-PCR was then performed on $2 \mu \mathrm{L}$ of $10 \times$ diluted cDNA (in a final volume of $20 \mu \mathrm{L}$ ) using iTaq Universal SYBR Green Supermix (Bio-Rad). Primers used for the amplification of the seven above-mentioned genes and the reference gene gyrA are supplied in supplementary data (Additional file 3: Table S3). PCR conditions were: $3 \mathrm{~min}$ at $95^{\circ} \mathrm{C}$ followed by 35 cycles of $15 \mathrm{~s}$ at $95^{\circ} \mathrm{C}$ and $30 \mathrm{~s}$ at $60^{\circ} \mathrm{C}$. Relative gene expression was calculated according to Pfaffl (2001) [48].

\section{Additional files}

Additional file 1: Table S1. Proteins produced by Streptomyces scabiel found in both casein-suberin and casein media.

Additional file 2: Table S2. Proteins specifically produced by Streptomyces scabiei in casein medium.

Additional file 3: Table S3. Primers used in this study for real-time RT-PCR.

\section{Abbreviations}

LC-MS/MS: Liquid chromatography-mass spectrometry/mass spectrometry; MW: Molecular weight; CM: Casein medium; CSM: Casein suberin medium.

\section{Competing interests}

The authors declare that they have no competing interests.

\section{Authors' contributions}

DK and RPR performed proteomics experiments and enzymatic assays. SL performed real-time RT-PCR experiments. AMSB analyzed proteomics data. CB supervised the project. All authors participated to the manuscript writing. All authors read and approved the final manuscript.

\section{Acknowledgements}

The authors thank Chantal Binda for reviewing the manuscript. This work is supported by the National Sciences and Engineering Research Council of Canada. DK was financially supported by a Ph.D. scholarship from the Ministry of Higher Education, Egypt.

\section{Author details}

'Centre SĖVE, Département de biologie, Université de Sherbrooke, Québec J1K 2R1, Canada. ${ }^{2}$ Department of Plant Pathology, Faculty of Agriculture, University of Alexandria, El-Shatby 21545, Egypt.

Received: 19 February 2014 Accepted: 30 May 2014 Published: 25 June 2014

\section{References}

1. Knief C, Delmotte N, Vorholt JA: Bacterial adaptation to life in association with plants - A proteomic perspective from culture to in situ conditions. Proteomics 2011, 11:3086-3105.

2. Lauzier A, Simao-Beaunoir A-M, Bourassa S, Poirier GG, Talbot B, Beaulieu C: Effect of potato suberin on Streptomyces scabies proteome. Mol Plant Pathol 2008, 9:753-762.

3. Joshi MV, Mann SG, Antelmann H, Widdick DA, Fyans JK, Chandra G, Hutchings MI, Toth I, Hecker M, Loria R, Palmer T: The twin arginine protein transport pathway exports multiple virulence proteins in the plant pathogen Streptomyces scabies. Mol Microbiol 2010, 77:252-271.
4. Beaulieu C, Goyer C, Beaudoin N: Interactions between pathogenic streptomycetes and plants: The role of thaxtomins. In Plant-Microbe Interactions. Edited by Ait Barka E, Clément C. Trivandrum: Research Signpost; 2008:117-133.

5. Lerat S, Simao-Beaunoir A-M, Wu R, Beaudoin N, Beaulieu C: Involvement of the plant polymer suberin and the disaccharide cellobiose in triggering thaxtomin a biosynthesis, a phytotoxin produced by the pathogenic agent Streptomyces scabies. Phytopathology 2010, 100:91-96.

6. Lerat S, Forest M, Lauzier A, Grondin G, Lacelle S, Beaulieu C: Potato suberin induces differentiation and secondary metabolism in the genus Streptomyces. Microbes Environ 2012, 27:36-42.

7. Bernards MA, Razem FA: The poly(phenolic) domain of potato suberin: A non-lignin cell wall bio-polymer. Phytochemistry 2001, 57:1115-1122.

8. Graça J, Pereira H: Suberin structure in potato periderm: glycerol, long-chain monomers, and glyceryl and feruloyl dimers. J Agric Food Chem 2000, 48:5476-5483.

9. Santos S, Cabral V, Graça J: Cork suberin molecular structure: Stereochemistry of the C18 epoxy and vic-diol $\omega$-hydroxyacids and, a, $\omega$-diacids analyzed by NMR. J Agric Food Chem 2013, 61:7038-7047.

10. Graça J, Santos S: Suberin: a biopolyester of plants' skin. Macromol Biosci 2007, 7:128-135.

11. Kontkanen H, Westerholm-Parvinen A, Saloheimo M, Bailey M, Rättö M, Mattila I, Mohsina M, Kalkkinen N, Nakari-Setälä T, Buchert J: Novel Coprinopsis cinerea polyesterase that hydrolyzes cutin and suberin. Appl Environ Microbiol 2009, 75:2148-2157.

12. Komeil D, Simao-Beaunoir A-M, Beaulieu C: Detection of potential suberinase-encoding genes in Streptomcyes scabiei strains and other actinobacteria. Can J Microbiol 2013, 59:294-303.

13. Prieto JH, Koncarevic S, Park SK, Yates J III, Becker K: Large-scale differential proteome analysis in Plasmodium falciparum under drug treatment. PLoS One 2008, 3:e4098.

14. Wilson DB: Microbial diversity of cellulose hydrolysis. Curr Opin Microbiol 2011, 14:259-263.

15. Douliez JP: Cutin ans suberin monomers are membrane perturbants. J Colloid Interface Sci 2004, 271:507-510.

16. Birkó Z, Swiatek M, Szájli E, Medzihradszky KF, Vijgenboom E, Penyige A Keseru J, Van Wezel GP, Biro S: Lack of A-factor production induces the expression of nutrient scavenging and stress-related proteins in Streptomyces griseus. Mol Cell Proteomics 2009, 8:2396-2403.

17. Kiss Z, Dobránszki J, Hudák I, Birkó Z, Vargha G, Biró S: The possible role of factor C in common scab disease development. Acta Biol Hung 2010 61:322-332.

18. Stark RE, Sohn W, Pacchiano RA Jr, Al-Bashir M, Garbow JR: Following suberization in potato wound periderm by histochemical and solid-state ${ }^{13} \mathrm{C}$ nuclear magnetic resonance methods. Plant Physiol 1994, 104:527-533.

19. Lombard V, Golaconda Ramulu H, Drula E, Coutinho PM, Henrissat B: The carbohydrate-active enzymes database (CAZy) in 2013. Nucleic Acids Res 2014, 42(D1):D490-D495.

20. Kumar R, Singh S, Singh OV: Bioconversion of lignocellulosic biomass: biochemical and molecular perspectives. J Ind Microbiol Biotechnol 2008, 35:377-391.

21. Akanuma G, Hara H, Ohnishi Y, Horinouchi S: Dynamic changes in the extracellular proteome caused by absence of a pleiotropic regulator AdpA in Streptomyces griseus. Mol Microbiol 2009, 73:898-912.

22. Lawoko M: Unveiling the structure and ultrastructure of lignin carbohydrate complexes in softwoods. Int J Biol Macromol 2013, 62:705-713.

23. Ogata H, Goto S, Sato K, Fujibuchi W, Bono H, Kanehisa M: KEGG: Kyoto Encyclopedia of Genes and Genomes. Nucleic Acids Res 1999, 27:29-34

24. Gupta R, Gupta N, Rathi P: Bacterial lipases: an overview of production, purification and biochemical properties. Appl Microbiol Biotechnol 2004 64:763-781.

25. Brockerhoff H: Model of interaction of polar lipids, cholesterol, and proteins in biological membranes. Lipids 1974, 9:645-650.

26. Sugihara A, Shimada $Y$, Nomura A, Terai $T$, Imayasu M, Nagai $Y$, Nagao T, Watanabe $Y$, Tominaga $Y$ : Purification and characterization of a novel cholesterol esterase from Pseudomonas aeruginosa, with its application to cleaning lipid-stained contact lenses. Biosci Biotechnol Biochem 2002, 66:2347-2355.

27. Du L, Huo Y, Ge F, Yu J, Li W, Cheng G, Yong B, Zeng L, Huang M: Purification and characterization of novel extracellular cholesterol esterase from Acinetobacter sp. J Basic Microbiol 2010, 50:S30-\$36. 
28. Xiang $H$, Masuo $S$, Hoshino $T$, Takaya N: Novel family of cholesterol esterases produced by actinomycetes bacteria. Biochim Biophys Acta 2007, 1774:112-120.

29. Boher P, Serra O, Soler M, Molinas M, Figueras M: The potato suberin feruloyl transferase FHT which accumulates in the phellogen is induced by wounding and regulated by abscisic and salicylic acids. J Exp Bot 2013, 64:3225-3236.

30. Serra O, Hohn C, Franke R, Prat S, Molinas M, Fiqueras M: A feruloyl transferase involved in the biosynthesis of suberin and suberinassociated wax is required for maturation and sealing properties of potato periderm. Plant J 2010, 62:277-290.

31. Topakas E, Vafiadi C, Christakopoulos P: Microbial production, characterization and applications of feruloyl esterases. Process Biochem 2007, 42:497-509.

32. Diaz E, Jiménez Jl, Nogales J: Aerobic degradation of aromatic compounds. Curr Opin Biotechnol 2013, 24:431-442.

33. Kathri BB, Tegg RS, Brown PH, Wilson CR: Temporal association of potato tuber development with susceptibility to common scab and Streptomyces scabiei-induced responses in the potato periderm. Plant Pathol 2011, 60:776-786.

34. Thangavel T, Tegg RS, Wilson CR: Enhanced suberin production in novel potato somaclones provides protective bio-barrier against two key scab diseases. Fremantle, Australia: Proceedings of the 7th Australasian Soilborne Diseases Symposium (ASDS); 2012:17-20. in press.

35. Bradford MM: A rapid and sensitive method for quantification of microgram quantities of protein utilizing the principle of protein-dye binding. Anal Biochem 1976, 72:248-254.

36. Lever M: A new reaction for colorimetric determination of carbohydrates. Anal Biochem 1972, 47:273-279.

37. Shevchenko A, Wilm M, Vorm O, Mann M: Mass spectrometric sequencing of proteins from silver-stained polyacrylamide gels. Anal Chem 1996, 68:850-858.

38. Havliš J, Thomas H, Šebela M, Shevchenko A: Fast-response proteomics by accelerated in-gel digestion of proteins. Anal Chem 2003, 75:1300-1306.

39. Claudel-Renard C, Chevalet C, Faraut T, Kahn D: Enzyme-specific profiles for genome annotation: PRIAM. Nucleic Acids Res 2003, 31:6633-6639.

40. Kanehisa M, Goto S, Kawashima S, Okuno Y, Hattori M: The KEGG resource for deciphering the genome. Nucleic Acids Res 2004, 32:D277-D280.

41. Tatusov RL, Koonin EV, Lipman DJ: A genomic perspective on protein families. Science 1997, 278:631-637.

42. Dehal PS, Joachimiak MP, Price MN, Bates JT, Baumohl JK, Chivian D, Friedland GD, Huang KH, Keller K, Novichkov PS, Dubchak IL, Alm EJ, Arkin AP: MicrobesOnline: an integrated portal for comparative and functional genomics. Nucleic Acids Res 2010, 38:D396-D400.

43. Käll L, Krogh A, Sonnhammer ELL: Advantages of combined transmembrane topology and signal peptide prediction-the Phobius web server. Nucleic Acids Res 2007, 35:429-432.

44. Petersen TN, Brunak S, Von Heijne G, Nielsen H: SignalP 4.0: discriminating signal peptides from transmembrane regions. Nat Methods 2011, 8:785-786.

45. Bendtsen JD, Kiemer L, Fausbøll A, Brunak S: Non-classical protein secretion in bacteria. BMC Microbiol 2005, 5:58.

46. Bendtsen JD, Nielsen $H$, Widdick D, Palmer T, Brunak S: Prediction of twin-arginine signal peptides. BMC Bioinformatics 2005, 6:167.

47. Rose RW, Brüser T, Kissinger JC, Pohlschröder M: Adaptation of protein secretion to extremely high salt concentrations by extensive use of the twin arginine translocation pathway. Mol Microbiol 2002, 5:943-950.

48. Pfaffl MW: A new mathematical model for relative quantification in real-time RT-PCR. Nucleic Acids Res 2001, 29:2002-2007.

doi:10.1186/1477-5956-12-35

Cite this article as: Komeil et al:: Comparative secretome analysis of Streptomyces scabiei during growth in the presence or absence of potato suberin. Proteome Science 2014 12:35.

\section{Submit your next manuscript to BioMed Central and take full advantage of:}

- Convenient online submission

- Thorough peer review

- No space constraints or color figure charges

- Immediate publication on acceptance

- Inclusion in PubMed, CAS, Scopus and Google Scholar

- Research which is freely available for redistribution

Submit your manuscript at www.biomedcentral.com/submit
Biomed Central 